This item was submitted to Loughborough's Research Repository by the author.

Items in Figshare are protected by copyright, with all rights reserved, unless otherwise indicated.

\title{
Chronic overheating in low carbon urban developments in a temperate climate
}

PLEASE CITE THE PUBLISHED VERSION

http://dx.doi.org/10.1016/j.rser.2016.09.106

PUBLISHER

(C) Elsevier

VERSION

AM (Accepted Manuscript)

\section{PUBLISHER STATEMENT}

This work is made available according to the conditions of the Creative Commons Attribution-NonCommercialNoDerivatives 4.0 International (CC BY-NC-ND 4.0) licence. Full details of this licence are available at: https://creativecommons.org/licenses/by-nc-nd/4.0/

\section{LICENCE}

CC BY-NC-ND 4.0

\section{REPOSITORY RECORD}

McLeod, Rob, and Michael Swainson. 2017. "Chronic Overheating in Low Carbon Urban Developments in a Temperate Climate”. Loughborough University. https://hdl.handle.net/2134/23659. 


\title{
Chronic OVerheating in LoW Carbon URBan Developments in a TEMPERATE CLIMATE
}

Robert S. McLeod ${ }^{\mathrm{A}}$, Michael Swainson ${ }^{\mathrm{B}}$

\author{
${ }^{A}$ Building Energy Research Group, Loughborough University, LE11 3TU \\ ${ }^{B}$ Building Research Establishment, Garston, Watford, WD25 9XX \\ Corresponding author: \\ Robert S. McLeod \\ Email: R.S.McLeod@lboro.ac.uk \\ Telephone: +44 (0) 1509228540
}

\section{ABSTRACT}

Numerous studies have reported on overheating in urban contexts the majority of which have focused on the influences of external factors, such as: heat waves and climatic change. To date very little research has examined the more insidious issue of chronic year-round overheating in temperate climatic zones.

The present study begins by reviewing the potential implications of planning and legislative constraints underlying urban residential design. A case study example is then introduced to examine the potential manifestation of such issues in practice. Detailed field monitoring and survey data from a number of newly built flats in a multi-residential block in London, is presented. Typical of a new generation of urban dwellings the development incorporates a high thermal specification together with low carbon building services, such as communal heating systems and mechanical ventilation with heat recovery. Through detailed zonal measurements of a broad range of environmental and building services parameters it has been possible to isolate the key factors underpinning poor overheating performance for these flats.

The findings of this case study are part of a larger research project investigating the causes of overheating in high density urban dwellings across Greater London. The results suggest that the causes of chronic overheating in these modern low-energy flats are multiple, but typically share common factors stemming from poorly integrated architectural and MEP design decisions. Conflicts between regional planning policies, UK building regulations, and health and safety legislation appear to be compounding the problem.

Keywords: communal heating systems; passive cooling; building performance evaluation (BPE); postoccupancy evaluation (PoE), thermal comfort; Housing Health and Safety Rating System (HHSRS) 


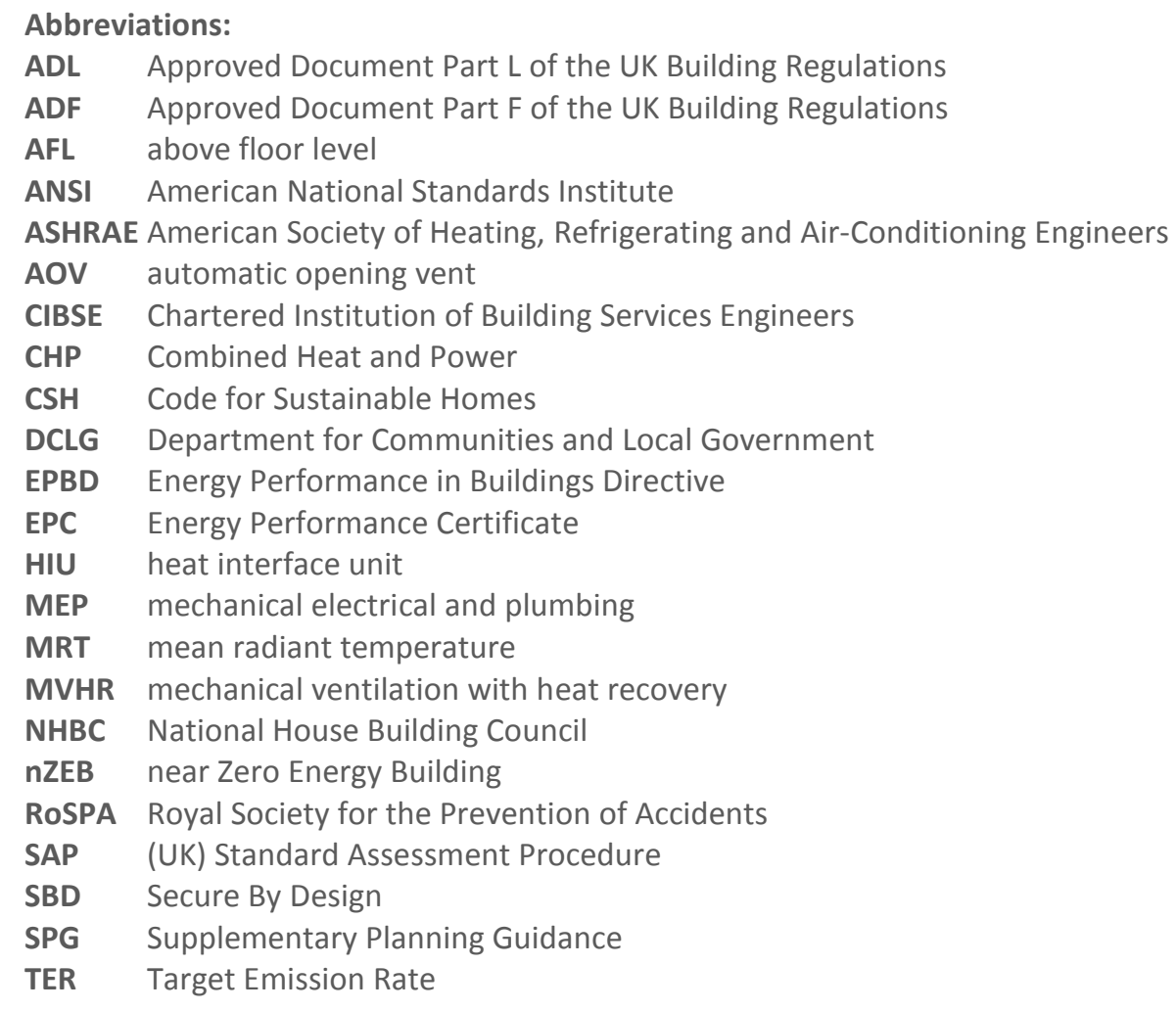

\subsection{INTRODUCTION}

There is a growing body of evidence, both from within the UK and across Europe, that modern energy efficient buildings are overheating [1] [2] [3] [4] [5] . In tandem complaints of thermal discomfort and reports of adverse health effects from the occupants of such buildings are rising [2] [6] [7]. The correlation between high energy efficiency ratings and increased risk of overheating is not always linear [8] and there is a need to consider site specific factors, such as: building services, glazing orientation, ventilation restrictions and usage patterns when evaluating the degree of risk [1] [4] [9] [6] [10].

Trends towards hotter than average summers and an increased frequency of extreme heat wave events [11] are obvious risk factors in relation to the increasing frequency of overheating in the built environment. Seasonal overheating and extreme events, such as the 2003 heat wave which is reported to have resulted in 2,000 heat related deaths in the UK, are well documented [12] [13] [12] [14] [15]. Such events must be distinguished from the phenomenon of 'chronic overheating' however which occurs when elevated internal temperatures extend well beyond the summer season and occupants are subjected to prolonged, and in some cases, year-round overheating. Although this phenomenon is growing and is widely known within the UK building services industry [2], such cases are typically resolved out-of-court and rarely enter the public domain.

According to CIBSE TM52, "overheating happens in a building either through bad design, poor management or inadequate services" [10, p. 1]. It is likely in many cases of chronic overheating that several of these key factors may co-exist. Although design issues are often highly context dependant; from the perspective of architects, building services engineers and developers it is critically important to understand how poor design integration may result in increased vulnerability to overheating. Similarly from a sustainable building policy perspective it is vital to understand in which areas policies may be interacting perversely as 'design drivers' in relation to exacerbating the risks of overheating.

Over the past decade a number of statutory and policy drivers (enacted at European, national and regional levels) are shaping the way U.K. architects, engineers and developers currently approach the remit of producing high density low carbon building design. A significant focus has been placed on the reduction of carbon emissions and this has largely been targeted at reducing heat losses through the thermal envelope[16] 
[17] as well as improving the efficiency of heating systems. The London Plan, which provides a statutory spatial development plan for Greater London, sets out specific policies to encourage the use of decentralised energy in new development proposals; which includes promoting the use of communal heating systems [18].

The potential implications of these design drivers have been documented in a number of comprehensive overheating reviews, including those carried out by the National House Building Council (NHBC) Foundation [2], the Zero Carbon Hub (ZCH) [18] and the Department for Communities and Local Government (DCLG) [3], and highlighted in performance evaluation studies of energy efficient buildings [4] [8] [19]. It is notable that in a survey comprising house building and public sector stakeholders interviewed in 2012 (as part of a DCLG review of overheating in dwellings) $100 \%$ of the respondents reported that, "they were aware, had seen, received complaints about or were concerned about overheating in flats built after 2002, especially those with communal heating systems [3, p96]."

This study illustrates the interaction of these compounding factors by investigating the causes of chronic overheating in a newly completed high density residential complex in Greater London. Through a detailed monitoring programme the research seeks to identify the dominant causes of prolonged overheating (occurring outside of the summer period) in a small number of flats and their adjoining communal areas selected form a larger complex. The research forms part of a wider investigation of the phenomenon of chronic overheating in modern energy efficient buildings across the Greater London region. For legal and ethical reasons the precise location and name of the development has been withheld.

\subsection{BACKGROUND - REVIEW OF OVERHEATING DRIVERS AND DEFINITIONS}

\subsection{POLICY AND LEGISLATIVE DRIVERS}

Over the past decade a number of legislative and policy drivers have been enacted at European, national and regional level which are shaping the way U.K. designers and engineers respond to the remit of designing low energy and low carbon residential buildings in urban areas. Many of these factors have been extensively documented in a number of comprehensive overheating reviews including those carried out by NHBC [2] and DCLG [3] in 2012 and ZCH in 2015 [5] as well as in performance evaluations of energy efficient buildings in relation to overheating risks [4] [19] . In summary these drivers can be broadly grouped into four main categories: i) those targeting higher fabric performance levels, ii) planning policies promoting low carbon communal and district heating systems, iii) drivers encouraging higher urban densities, along with iv) health and safety guidance and legislation.

Enforcement of energy performance standards for new residential buildings in relation to minimising fabric transmission losses, airtightness and operational carbon emissions falls under the UK Building Regulations Approved Document L (AD L1A) - Conservation of Fuel and Power [20]. The 2006 revision of AD L1A saw the imposition of Target Emission Rates (TERs) for all new dwellings as well as the introduction of a design air permeability limit of $10 \mathrm{~m}^{3} /\left(\mathrm{h} . \mathrm{m}^{2}\right)$ at $50 \mathrm{~Pa}$ [21]. This legislative standard became the baseline for the higher levels of energy conservation mandated under the Code for Sustainable Homes (CSH) which was introduced as a voluntary sustainability initiative, in April 2007. From April 2008 all dwellings built with the assistance of public finance in the UK were obliged to meet CSH Level 3, which represented a further $25 \%$ reduction in a buildings' Design Emission Rate (DER) beyond the statutory minimum TER value imposed by AD L1A [22]. As a result of this funding policy an increasing number of social housing providers and private developers began to voluntarily build to even higher fabric performance standards [23] [24] in order to improve their CSH ratings and progressively upskill their supply chains towards delivering the 2016 Zero Carbon target for new homes in the UK. 
Following a review of the legislative burdens imposed on UK housing developers in July 2015, the UK Treasury announced that the CSH and existing Zero Carbon homes methodologies would be abandoned [25]. Despite these overarching policy revisions recent updates to London's Supplementary Planning Guidance (SPG) continues to promote high standards of energy efficiency and the Zero Carbon concept [26]. The London Housing SPG defines 'Zero Carbon' homes as, "homes forming part of major development applications where the residential element of the application must achieve at least a 35 per cent reduction in regulated carbon dioxide emissions (beyond Part L 2013) on-site" [27, p12], with the remaining (AD L) regulated carbon dioxide emissions to be off-set via a fiscal contribution to the relevant borough [27].

The improved retention of thermal energy implicated by improvements to AD $L$ must be considered in the light of changes to Approved Document F (AD F) Ventilation. In a review of the evidence of overheating in new homes Dengel and Swainson point out that despite substantial tightening of the background airtightness and fabric requirements in $A D L(2006)$ there were no substantive changes to the means or rate of ventilation specified in AD F [2]. The 2006 edition of AD F refers to fabric air permeability's of around $3-4 \mathrm{~m}^{3} / \mathrm{h} \cdot \mathrm{m}^{2}$ (envelope area at a 50 Pascal pressure difference) as providing the basis for its prescribed ventilation rates. AD $F$ advises that, "Where special measures are to be taken to achieve greater air tightness, additional ventilation provisions may be required" [28, p7]. However the advice in AD F stops short of defining 'additional provisions' or describing how their efficacy can be evidenced.

In relation to purge ventilation Appendix B of AD F [28] specifies that the area of the opening should be at least $1 / 20^{\text {th }}$ of the floor area of the room in the case of hinged, pivot or sliding sash windows that are capable of opening $30^{\circ}$ or more. For windows that open less than $30^{\circ}$, the area of the opening should be at least $1 / 10^{\text {th }}$ of the floor area of the room. According to AD F (2006) the required proportion of the floor area is determined by the opening angle of the largest window in the room. The limitations of this approach in relation to over estimating the ventilation purging capacity of windows with heavily restricted opening angles were subsequently addressed in the 2010 edition of AD F, which clarified that, "window which were limited to an opening angle of $15^{\circ}$ or less would not be suitable for purge ventilation" [29]. AD F (2010) states that when this purge ventilation design guidance is adhered to a purge ventilation target rate of $4 \mathrm{~h}^{-1}$ should be achievable in most cases. This assumption is in turn referenced to guidance found in the British Standard BS 5925 -AMD 8930 [30] which is based upon a number of defined modelling assumptions about the nature of the building and it's boundary conditions.

The evolution of UK safety legislation driven by the Royal Society for the Prevention of Accidents (RoSPA) combined with crime prevention initiatives such as Secured by Design (SBD) has unintentionally created a further impediment to the use of natural purge ventilation strategies in the urban context. As a result of such initiatives window stay restrictors are now installed by default on most new social and private market dwellings in the UK. BS 8213 [31, Para 5.4.1] recommends the fitting of safety restrictors to all accessible opening lights where children or adults are at risk of falling out. Paragraph 3.14 [31] defines a safety restrictor as a mechanical device, which is intended to limit the initial movement of an opening light so that a clear opening of not more than $100 \mathrm{~mm}$ is achieved at any point. In practice this guidance means that most windows containing fixed stay restrictors are unlikely to meet the (AD F) $15^{\circ}$ threshold criteria for purge venting, unless the restrictor can be easily removed.

In addition to problems related to the reduced capacity to purge ventilate there have been a number of drivers that may be contributing to higher internal heat load densities in urban dwellings. Policy 5.6 of the London Plan encourages the use of decentralised energy in all new development proposals. Connecting to existing heating or cooling networks, installing Combined Heat and Power (CHP) and the use of communal heating and cooling are encouraged under this policy [32]. GLA guidance on preparing energy assessments requires that all planning applicants work on the assumption that a site heat network will be required [27]. The only exceptions to this requirement occur where it can be clearly demonstrated that it is not applicable due to local circumstances.

Contiguously Policy 5.9 of the London Plan states that major development proposals should reduce potential overheating and reliance on air conditioning systems and demonstrate this by minimising internal heat generation through energy efficient design, as well as reducing the amount of heat entering a building in summer [32]. The potential for substantial conflict between policies 5.6 and 5.9 of the London Plan is not clearly identified however. Although the GLA acknowledges that poorly designed heat network infrastructure 
within a building can contribute towards overheating problems [27], it does not explicitly warn developers of the specific risks associated with such installations in the context of highly insulated airtight buildings.

At the spatial planning level, densification policies in many urban areas of the UK are being tightened. In the March 2016 Budget, the UK government announced its plans to expand the power of city regions in order to permit the development of additional storeys on existing buildings, in order to increase densities on brownfield land [33]. At the same time new proposals have been announced to incentivise house building in London, with the aim of producing 400,000 new homes within the next 5 years [25]. Higher density residential development, and a contiguous reduction in internal floor areas are likely to have a direct impact on internal heat gain densities.

Population demographics bring a further social dimension to overheating that cannot be ignored. Globally occupants are spending a greater percentages of time within dwellings [34] and this trend will inevitably contribute to higher internal heat gain densities as well as increased exposure to overheating risks. In addition the UK population is aging and it is established that the elderly (over 75 year old) have an elevated vulnerability to heat related mortality and morbidity [13]. Whilst energy consumed for space heating and hot water consumption in UK homes has remained largely static in recent decades the net energy consumption by UK households has risen by $18 \%$ in the past 40 years [35]. A continual rise in lighting and appliance energy consumption is responsible for the majority of this increase [35] and this will have a direct impact on internal heat gains [36].

According to CIBSE TM52 [37] overheating in buildings will become a bigger concern in a future characterised by climatic changes and global energy insecurity, which will make the control of indoor climate increasingly challenging. This situation makes it especially important to have clear guidelines or regulations that use an appropriate definition of overheating to avoid buildings being wrongly assessed. Clear assessment benchmarks will not help to prevent overheating however unless there is a congruent process for assessing the likelihood of overheating in the very earliest stages of a buildings design progression. Although there are a number of industry guidance documents and legislative procedures in place in the UK to prevent overheating occurring the rising prevalence of reported overheating in new dwellings [2] [3] [5] [38] raises questions about whether current procedures are working effectively.

\subsection{OVERHEATING THRESHOLDS}

Overheating in the built environment is a concept which has been largely subsumed within the related field of thermal comfort. Thermal comfort itself is often described as, "the condition of mind that expresses satisfaction with the thermal environment" [39] and has been historically assessed by occupant surveys involving subjective evaluation methods. Thus the criteria used to parameterise and quantify overheating assessment models have largely evolved from occupant studies of thermal comfort; many of which were carried out on healthy young population samples in the context of offices, schools and commercial buildings [40] [41] [42] or in tightly controlled climatic chambers [43] [44]. By extension 'overheating' has been variously defined as occurring at a given temperature or when a combination of environmental parameters exceed a given threshold, beyond which occupants increasingly experience discomfort.

Two dominant models have evolved from this concept to assist the implementation of thermal comfort assessments: The 'deterministic model' uses a parametrized mathematical model to categorize the predicted level of thermal comfort according to a number of environmental parameters. This model is widely applied to thermal comfort assessments in mechanically conditioned spaces, and is described in EN ISO 7730 [45] and ANSI/ ASHRAE 55 [39]. A second model known as the 'adaptive model' is predominantly used to assess thermal comfort in 'free running' naturally ventilated buildings. The adaptive model is founded in the theory that tolerance to extreme temperatures increases with adaptation (i.e. length of exposure time). Hence the adaptive model varies its assessment thresholds in accordance with the running mean of the daily external air temperature. This approach is detailed in EN 15251 [44] and further elaborated in CIBSE TM52 [36].

Some researchers have argued that thermal comfort approaches do not provide a reliable basis for conducting overheating risk assessments since they are not based on occupant health but are grounded in the concept of 'thermal preference' [4] [26]. Epidemiological evidence for heat related mortality in London, assessed as part 
of a governmental review in 2012 , shows that a daily external maximum temperature of around $24.7^{\circ} \mathrm{C}$ is closely correlated with a clear threshold for elevated mortality rates [3]. In support of an occupant health based approach, studies have shown that the elderly often report feeling comfortable at temperatures which are not, in fact, healthy for them [46] [47]. Research collated by the World Health Organisation (WHO) in relation to acceptable internal air temperatures in buildings has primarily focused on safeguarding human health [48] [49] [50]. WHO research concludes that there is minimal risk to the health of sedentary people, including the elderly, in dwellings where the ambient temperature is within the range of $18^{\circ} \mathrm{C}-24^{\circ} \mathrm{C}$ [ 49 ].

In order to provide a statutory basis for evaluating the health and safety risks originating from deficiencies in dwellings the UK Government introduced the Housing Health and Safety Rating System (HHSRS) in 2005 [51]. Judgements under the HHSRS are considered legally enforceable when they could result in harm to a member of a relevant vulnerable group [52]. Consequently the health implications of 'excess heat' have a statutory definition under the HHSRS, which states that, "High temperatures can increase cardiovascular strain and trauma, and where the temperatures exceed $25^{\circ} \mathrm{C}$, mortality increases and there is an increase in strokes" [50, p64]. Since this is the only statutory definition of overheating in relation to the indoor environment in the UK, it has been used in the case study analysis (Section 4) as a threshold indicator of overheating in vulnerable populations. This legislation is often overlooked by building developers and designers, but it is significant since it marks the point beyond which they could be held liable for creating an indoor environment engendering risks to human health.

\subsection{Methodology}

This study aims to assess the extent and causes of chronic overheating in a large (circa 80 unit) newly built multi-story residential development located in North London. The study was initiated in response to numerous complaints received by the building owner's management group in relation to reports of chronic overheating in individual flats and communal areas occurring within the initial twelve month operational period. In this paper, the results of the detailed analysis of three flats are presented that were selected based on a number of objectives.

One of the initial objectives of the study was to establish which zones of the building were most affected by overheating. To support the qualitative feedback from the occupants an initial infra-red thermographic imaging survey was undertaken in the communal areas at each floor level of the building. From this survey it was possible to isolate the zones most affected by overheating and on this basis individual flats where then selected for inclusion in the detailed monitoring study.

The second objective of the study was to determine the magnitude and causal factors influencing the degree of overheating, and to establish whether common factors were involved. In order to achieve this objective the flats, surrounding communal areas and individual building services components where subject to a detailed monitoring protocol at a relatively high spatial resolution (Table 3, Figures 6-8). Preference was given to monitoring unoccupied flats initially in order to evaluate the performance of the building and it's systems without the stochastic influence of occupant behaviour.

Although monitoring unoccupied dwellings is likely to reflect lower internal gains compared to an inhabited dwelling it provides the opportunity to evaluate the building fabric and communal building services performance independently from the influence of occupant behaviour. A further benefit of this approach is that it permits the timed intervention of specific ventilation strategies to be assessed in a controlled manner during the monitoring regime. Since the most pronounced overheating (both from occupant feedback and the thermographic study) was registered in the first and higher floors, a suitable unoccupied dwellings was selected on the first floor (Flats B) and second floor (Flat C). A ground floor dwelling (Flat A) was selected as a control study. Flat $A$ also had a double sided (east-west) aspect which allowed for complete cross ventilation (Figure 1). These design characteristics, supported by data from the initial thermal imaging study, suggest that Flat A was likely to be one of the best performing dwellings in the overall complex.

Monitoring was undertaken during the autumn shoulder season (in October, 2015) in order to avoid the influence of peak summer temperatures obscuring the underlying overheating profile. A similar monitoring 
protocol was applied to each flat and to the contiguous communal areas. Since external micro climatic conditions are known to be highly localised in the vicinity of urban heat islands [56] [57]. A shaded external weather transmitter (housed within a Stevenson screen) recording outside air temperature $\left(\mathrm{T}_{\text {mand }}\right)$ and relative humidity (RH) data was installed on the external façade of the ground floor (control) flat. The use of monitored ambient data also enabled comparison with long term weather data statistics from the nearest meteorological recording centre (Hampstead).

The final objective of the research was to establish whether the overheating risk had been correctly identified at the time of construction. Once the results had been analysed they were compared to the overheating modelling predictions contained in the Standard Assessment Procedure (SAP) reports (a requirement of Part $L$ of the UK Building Regulations).

The thermal specification of the flats and the monitoring set up (including sensor locations) will be explained in greater detail in the following sections.

\subsection{CASE STUDY}

Built to comply with the 2010 revision of Part L of the UK Building Regulations, the development uses a construction typology typical of many new residential developments across London. The building's facades are highly glazed and of masonry construction, using a partly filled cavity wall with brick external cladding. The thermal properties, and air tightness of the fabric of each flat were recorded during the SAP assessment, and a summary of the key thermal values for the principle construction elements is provided in Table 1 [53]. A design summary highlighting the principal characteristics of each flat in relation to orientation, aspect, storey height and ventilation strategy is provided in Table 2.

TABle 1. Summary of thermal Properties of flats (ACCORding to project SAP ASSESSments)

\begin{tabular}{|c|c|}
\hline \multicolumn{2}{|c|}{ Flat A - Ground floor } \\
\hline Thermal element & Mean value \\
\hline External walls (U-value) & $0.27 \mathrm{~W} / \mathrm{m}^{2} \mathrm{~K}$ \\
\hline Party walls (U-value) & $0.2 \mathrm{~W} / \mathrm{m}^{2} \mathrm{~K}$ \\
\hline Ground Floor (U-value) & $0.21 \mathrm{~W} / \mathrm{m}^{2} \mathrm{~K}$ \\
\hline Roof (U-value) & (N/A - internal ceiling/floor) \\
\hline Glazed openings ( $U$-value) & $1.81 \mathrm{~W} / \mathrm{m}^{2} \mathrm{~K}$ \\
\hline Glazing ( $g$-value) & 0.63 \\
\hline Air permeability (@50Pa) & $4.72 \mathrm{~m}^{3} / \mathrm{m}^{2} . \mathrm{h}$ (tested) \\
\hline \multicolumn{2}{|c|}{ Flat B - 1st floor } \\
\hline Thermal element & Mean value \\
\hline External walls (U-value) & $0.26 \mathrm{~W} / \mathrm{m}^{2} \mathrm{~K}$ \\
\hline
\end{tabular}




\begin{tabular}{|c|c|}
\hline Party walls (U-value) & $0.2 \mathrm{~W} / \mathrm{m}^{2} \mathrm{~K}$ \\
\hline Ground Floor (U-value) & (N/A - internal floor) \\
\hline Roof (U-value) & $0.13 \mathrm{~W} / \mathrm{m}^{2} \mathrm{~K}$ \\
\hline Glazing (U-value) & $1.81 \mathrm{~W} / \mathrm{m}^{2} \mathrm{~K}$ \\
\hline Glazing ( $g$-value) & 0.63 \\
\hline Air permeability (@50Pa) & $6.6 \mathrm{~m}^{3} / \mathrm{m}^{2}$.h (average by type) \\
\hline \multicolumn{2}{|c|}{ Flat $\mathrm{C}-2$ nd floor } \\
\hline Thermal element & Mean value \\
\hline External walls (U-value) & $0.28 \mathrm{~W} / \mathrm{m}^{2} \mathrm{~K}$ \\
\hline Party walls (U-value) & $0.2 \mathrm{~W} / \mathrm{m}^{2} \mathrm{~K}$ \\
\hline Ground Floor (U-value) & (N/A - internal floor) \\
\hline Roof (U-value) & (N/A - internal ceiling/floor) \\
\hline Glazing ( $U$-value) & $1.81 \mathrm{~W} / \mathrm{m}^{2} \mathrm{~K}$ \\
\hline Glazing ( $g$-value) & 0.63 \\
\hline Air permeability (@50Pa) & $6.6 \mathrm{~m}^{3} / \mathrm{m}^{2} . \mathrm{h}$ (tested) \\
\hline
\end{tabular}


Table 2. Principal characteristics - orientation, aspect, storey height and Ventilation strategies

\begin{tabular}{|c|c|}
\hline \multicolumn{2}{|c|}{ Flat A } \\
\hline Storey level & Ground floor \\
\hline Principle solar orientation & East and West facing \\
\hline Aspect & Double sided \\
\hline Mechanical ventilation & $\begin{array}{l}\text { Decentralised constant volume MVHR with } \\
\text { summer- bypass }\end{array}$ \\
\hline Purge ventilation & $\begin{array}{l}\text { Inward opening windows and doors with safety } \\
\text { restrictors limiting opening thresholds to }<15^{\circ}\end{array}$ \\
\hline \multicolumn{2}{|c|}{ Flat B } \\
\hline Storey level & First floor \\
\hline Principle solar orientation & West facing \\
\hline Aspect & Single sided \\
\hline Mechanical ventilation & $\begin{array}{l}\text { Decentralised constant volume MVHR with } \\
\text { summer- bypass }\end{array}$ \\
\hline Purge ventilation & $\begin{array}{l}\text { Inward opening windows and doors with safety } \\
\text { restrictors limiting opening thresholds to }<15^{\circ}\end{array}$ \\
\hline \multicolumn{2}{|c|}{ Flat C } \\
\hline Storey level & Second floor \\
\hline Principle solar orientation & East facing \\
\hline Aspect & Single sided \\
\hline Mechanical ventilation & $\begin{array}{l}\text { Decentralised constant volume MVHR with } \\
\text { summer- bypass }\end{array}$ \\
\hline Purge ventilation & $\begin{array}{l}\text { Inward opening windows and doors with safety } \\
\text { restrictors limiting opening thresholds to }<15^{\circ}\end{array}$ \\
\hline
\end{tabular}

The overall development is split into four blocks each served by a stair/lift core, with the majority of the flats having either an east, west or south facing aspect. From the total number of available dwellings put forward by the developer for monitoring and an initial infra-red survey of the building, three flats were identified as being vacant and having sufficiently distinct characteristics to merit inclusion in this monitoring study. The purpose of prioritising vacant flats was twofold: firstly it permitted a large number of monitoring sensors to be deployed in areas which might otherwise be prone to occupant interference, and secondly it enabled the flats 
to be monitored under controlled conditions. The position of the monitored dwellings is indicated on the Upper Ground Floor layout shown in Figure 1. This selection of monitored flats allowed the influence of two different solar orientations and floor levels to be studied in comparison to a double sided ground floor 'control' dwelling (Flat A).

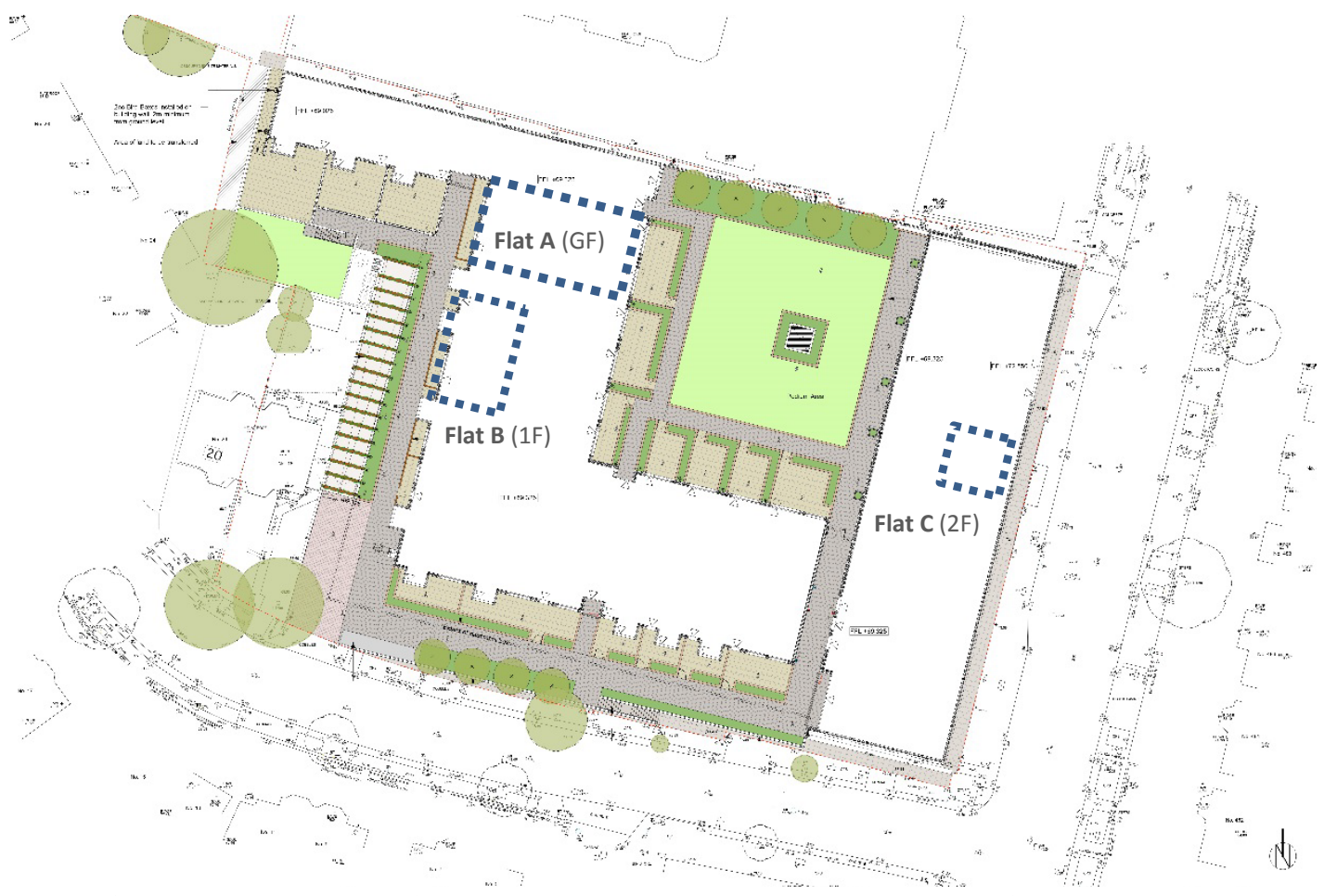

Figure 1. General Arrangement - Showing indicative positions of flats A, B and C

\section{FLAT A (CONTROL) - DESCRIPTION}

Flat $A$ is an east-west facing double sided upper ground floor flat. The occupants were in residence at the beginning and end of the monitoring period, but absent for a continuous ten day period in the middle during which Flat A operated as a 'control' for the other flats. This allowed contiguous periods where both the occupied and unoccupied conditions could be studied (Figure 9). The bedrooms of the flat face east, overlooking the central courtyard whilst the living and dining rooms face west into a communal garden area. The flat has one shared party wall to the south, with access from a communal corridor to the north which is reached via an internal courtyard.

The wet rooms (kitchen, bathroom, en-suite and utility room) are located off a central hallway in the flat, along with the Mechanical Ventilation with Heat Recovery (MVHR) unit and the communal heating system Heat Interface Unit (HIU), which are contained in separate cupboards. Ventilation of the flat is via a decentralised MVHR unit (an approach common to all of the dwellings in this development). The exposed MVHR ducts are all flexible and uninsulated and connect to rigid rectangular ducting within the ceiling void. The fresh air intake and exhaust for the ventilation system are located on the west elevation. The fresh air intake and exhaust terminals for the ventilation system are located on the west elevation, both terminals are comprised of single air bricks located flush with the building facade.

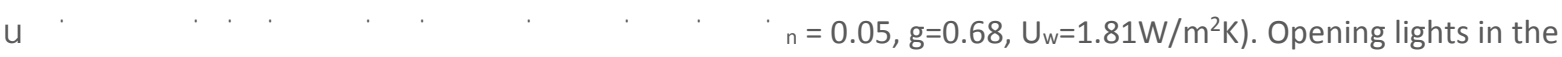
bedrooms are full-height patio doors (there being no opening windows). In Bedroom 1 there are double opening doors, with one side being tilt and turn, hinged at the bottom to allow opening of the door inwards at the top. In Bedroom 2 there is a single opening door, tilt and turn, hinged at the bottom to allow opening of the door inwards at the top. In the dining room there is a single opening light, top hung. In the living room there is an opening window light and a patio door. All windows and doors have opening restrictors/ safety stays installed, which in every case limits the opening angle to substantially less than $15^{\circ}$ (Figure 2 ). 


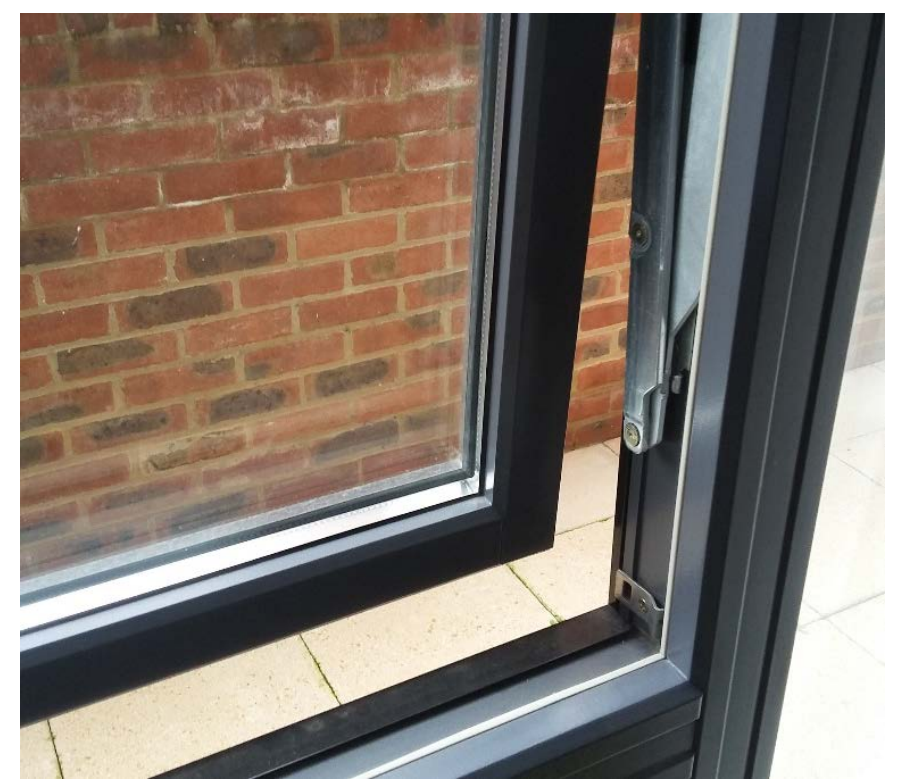

Figure 2. Restricted Window opening threshold, Flat A Living Room

Heating and hot-water provision are via a Heat Interface Unit (HIU) which is supplied from a communal heating system. A secondary circuit from the HIU supplies an underfloor heating system, however the underfloor heating circuit was turned off throughout the monitoring period. The pipes serving the HIU within the flat are insulated (Figure 3), however this appears to have been applied as a remedial measure. It is unknown whether the pipes within the ceiling void are insulated.

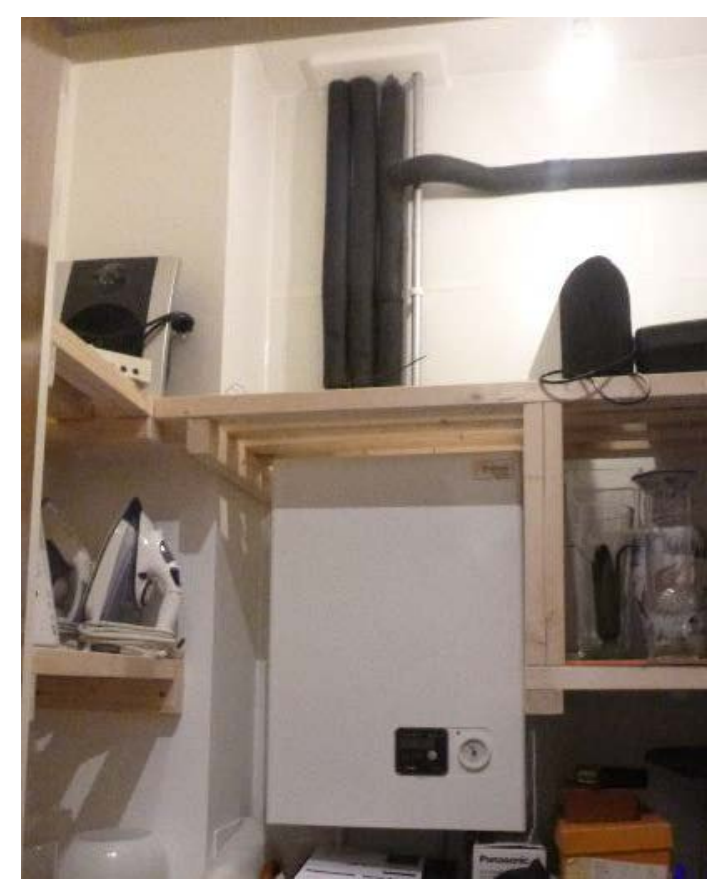

Figure 3. HIU ShoWing insulated heating System pipes (FLAt A)

\section{FLAT B - DESCRIPTION}

Flat $B$ is a two bedroom flat on the second floor which remained unoccupied throughout the monitoring period. The flat has a single external elevation which faces to the west, overlooking neighbouring gardens 
below. The flat has shared party walls to the north, south and east. Access is from a communal corridor to the east which passes through the building from Core number 2, where there is lift and stair access to the ground floor. The wet rooms (kitchen, bathroom, en-suite) are located on the east side of the flat adjacent to the party wall. The kitchen is open plan and connects to the west facing living room. Building services (MVHR and HIU) are contained in a large cupboard located off the central hallway.

Ventilation of the flat is by a MVHR unit. All of the ducts connected to the MVHR are flexible and uninsulated and pass through the ceiling to connect with rigid rectangular ducting within the ceiling void. The fresh air intake and exhaust terminals for the ventilation system are located on the west elevation, both are via single air bricks located flush with the building facade.

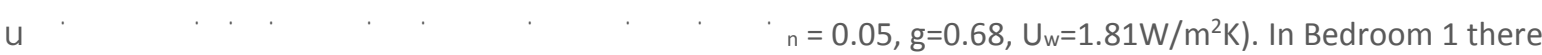
is a single patio door, with a tilt-and-turn opening mechanism, hinged at the bottom to allow opening of the door inwards at the top. In Bedroom 2 there is a single window, with a tilt only opening, hinged at the bottom to allow inward opening at the top. In the dining room there is a single patio door, with a tilt-and-turn opening, hinged at the bottom to allow opening of the door inwards at the top. All windows and doors have opening restrictors/ safety stays installed, which limits the opening angle to less than $15^{\circ}$ in all cases.

Heating and hot-water provision are via a Heat Interface Unit (HIU) which is supplied from the communal heating system. A secondary circuit from the HIU supplies an underfloor heating system, which was turned off during the monitoring period. The pipes serving the HIU within the flat had not been insulated, although they had all been painted using a low emissivity silver paint. It is unknown if the heating and DHW pipes within the ceiling void are insulated.

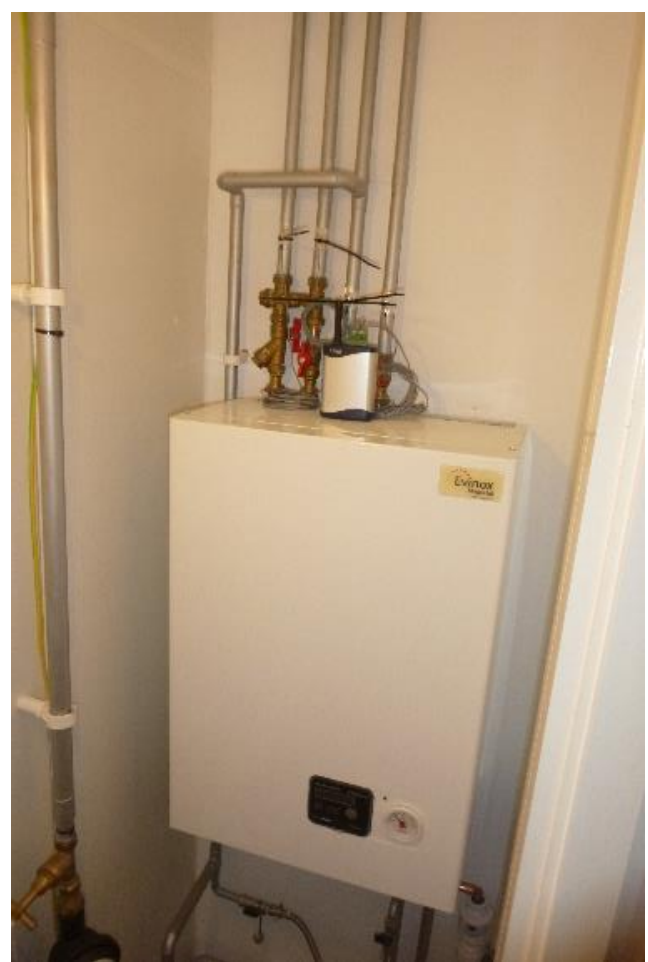

FiguRE 4. HIU - SHOWING UNINSULATED HEATING SYSTEM PIPEs (FLAT B)

\section{FLAT C - DEscription}

Flat $\mathrm{C}$, is a one bedroom flat on the second floor and was unoccupied throughout the monitoring period. The flat has a single external elevation, and faces to the east, overlooking a busy thoroughfare. The flat has shared party walls to the north, south and west. Access is from a communal corridor to the west which passes through the building from a central core, where there is lift and stair access to the ground floor. The wet rooms (kitchen and bathroom) are located on the west side of the flat adjacent to the party wall. The kitchen is 
open plan and connects to the east facing living room. The building services (MVHR and HIU) are contained in a large cupboard which is located off the central hall.

Ventilation of the flat is by a MVHR. The ducts connected to the MVHR are all flexible and pass through the ceiling and connect to rigid rectangular ducting within the ceiling void. The fresh air intake and exhaust for the ventilation system are located on the east elevation, both are through single air bricks located flush with the building facade.

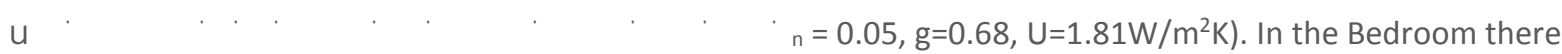
is a single full height window, opening being tilt only, hinged at the top to allow opening outwards at the bottom. In the dining/living room there is a single patio door, opening being tilt and turn, hinged at the bottom to allow opening of the door inwards at the top. All windows and doors have opening restrictors/ safety stays installed, which in every case limits the opening angle to substantially less than $15^{\circ}$.

Similarly to Flats A and B the heating and hot-water provision are via a Heat Interface Unit (HIU) which is supplied from the communal heating system. A secondary circuit from the HIU supplies an underfloor heating system, which was turned off during the monitoring period. The pipes serving the HIU within the flat had not been insulated, although they had all been painted silver. It is unknown whether the pipes within the ceiling void are insulated.

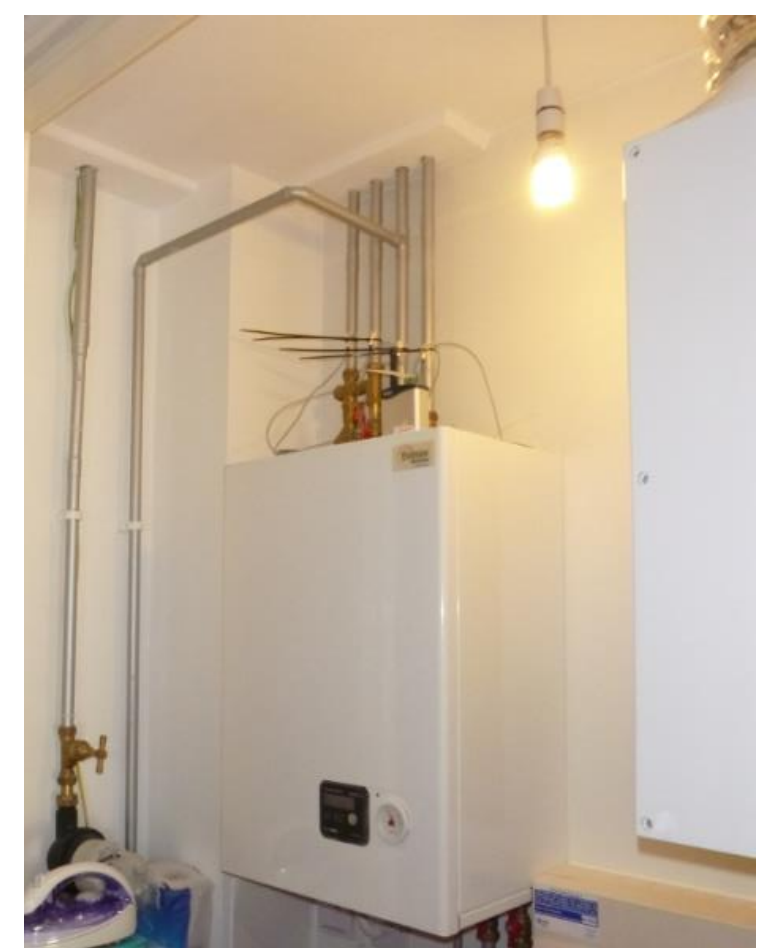

Figure 5. HIU - ShoWing UNINSULATEd heATING SYSTEM PIPES AND MVHR UNIT IN SHAREd SERVICES CUPBoARd (FLAT C)

Figure 5 illustrates a common design feature (found in both Flat B and C) wherein the HIU (and associated high temperature pipework) share a common building services cupboard with the MVHR unit. This design configuration is common in small flats (where storage space is limited) but creates an arrangement where the MVHR unit is likely to pick up unwanted heat gains whilst functioning in summer bypass mode.

\subsection{MONITORING SET-UP}

\section{EXPERIMENTAL SET-UP}

The thermocouples and wireless transmitters used in the study were randomly 'pair tested' prior to installation in order to ensure that they were reading accurately. This process involved placing selected 
thermocouples side by side at ambient room temperature and systematically checking that at all of sensors and transmitters used were reading within an acceptable tolerance of each other. This sensor checking procedure showed that all of the pair tested sensors and wireless transmitters were reading within a $\pm 0.1^{\circ} \mathrm{C}$ tolerance of one another. This level of accuracy was well within the manufacturers stated tolerance of $\pm 0.2^{\circ} \mathrm{C}$ [54] [55]. Table 3 identifies the types of sensors used, the location in which they were installed, the sensor shielding procedure deployed and the purpose of the corresponding data measurements.

External air temperatures are known to be highly localised in the vicinity of urban heat islands [56] [57]. A shaded external weather transmitter (housed within a Stevenson screen) recording outside air temperature $\left(\breve{\Gamma}_{\mathrm{GCO}}\right)$ and relative humidity $(\checkmark)$ data was installed on the external façade of the ground floor (control) flat. The use of monitored ambient data also enabled comparison with long term weather data statistics from the nearest meteorological recording centre (Hampstead).

TABle 3. Sensor Location and VARiables monitored

\begin{tabular}{|c|c|c|}
\hline Location & Sensor installed & Comments \\
\hline \multicolumn{3}{|c|}{ All flats } \\
\hline Living room & $\begin{array}{l}\text { Air temperature and relative } \\
\text { humidity (RHT transmitter) }\end{array}$ & \multirow{3}{*}{$\begin{array}{l}\text { Temperature and Relative } \\
\text { Humidity of habitable rooms }\end{array}$} \\
\hline Kitchen & $\begin{array}{l}\text { Air temperature and relative } \\
\text { humidity (RHT transmitter) }\end{array}$ & \\
\hline Bedrooms & $\begin{array}{l}\text { Air temperature and relative } \\
\text { humidity (RHT transmitter) }\end{array}$ & \\
\hline $\begin{array}{l}\text { HIU; Primary heating water inlet } \\
\text { and outlet, DHW and DCW inlets }\end{array}$ & $\begin{array}{l}\text { T-type thermocouple sensor (foil } \\
\text { shielded) taped directly to pipes }\end{array}$ & $\begin{array}{l}\text { Temperature of primary source of } \\
\text { heat in unoccupied flats and } \\
\text { assessment of system use in } \\
\text { partly occupied (control) flat. }\end{array}$ \\
\hline $\begin{array}{l}\text { MVHR; fresh air inlet, supply air } \\
\text { outlet, extract air inlet and } \\
\text { exhaust air outlet }\end{array}$ & $\begin{array}{l}\text { Probe thermistor sensor in } \\
\text { airstream }\end{array}$ & $\begin{array}{l}\text { Assessment of operation of } \\
\text { MVHR and ability to provide cool } \\
\text { fresh air to habitable rooms. }\end{array}$ \\
\hline $\begin{array}{l}\text { Living room fresh air (FA) supply } \\
\text { into room from MVHR }\end{array}$ & $\begin{array}{l}\text { T-type thermocouple sensor (foil } \\
\text { shielded) placed inside supply } \\
\text { valve }\end{array}$ & $\begin{array}{l}\text { Assessment of cool fresh air } \\
\text { provision via MVHR system. }\end{array}$ \\
\hline $\begin{array}{l}\text { Living room } \\
\text { (1.1 m height above FFL) }\end{array}$ & $\begin{array}{l}\text { Mean Radiant temperature (T- } \\
\text { type thermocouple black taped) } \\
\text { Air temperature (T-type } \\
\text { thermocouple foil shielded) }\end{array}$ & $\begin{array}{l}\text { Assessment of solar gain to room } \\
\text { Assessment of air temperature at } \\
\text { sitting head height }\end{array}$ \\
\hline $\begin{array}{l}\text { Living room } \\
\text { (0.1 m height above } \mathrm{FFL})\end{array}$ & $\begin{array}{l}\text { Air temperature (T-type } \\
\text { thermocouple foil shielded) }\end{array}$ & Air temperature at ankle height \\
\hline \multicolumn{3}{|c|}{ Corridors (outside flats being monitored) } \\
\hline Corridor & $\begin{array}{l}\text { Air temperature and relative } \\
\text { humidity }\end{array}$ & $\begin{array}{l}\text { Temperature and Relative } \\
\text { Humidity of the occupied space }\end{array}$ \\
\hline
\end{tabular}


Corridor ceiling void access through hatch outside front door of flat.

Soffit of structural slab, heating system distribution pipe and air temperature within void
Surface temperature (T-type thermocouple foil shielded) placed on pipes and soffit.
Assessment of the heating of the structural slab of the building and heat discharge from the heating system distribution pipes passing through the ceiling void

Air temperature sensor

External (outside flats being monitored)

\begin{tabular}{|l|l|l|}
\hline External façade (shaded location) & $\begin{array}{l}\text { Weather sensor (U-type } \\
\text { thermistor), logging air } \\
\text { temperature and relative } \\
\text { humidity }\end{array}$ & $\begin{array}{l}\text { Temperature and relative } \\
\text { humidity of ambient external air }\end{array}$
\end{tabular}

Prior to defining the monitoring protocol described above, a further detailed Infra-red (IR) survey was carried out in each zone of the monitored dwellings and throughout the adjoining communal access areas. The purpose of the IR survey was to identify any specific zones and service runs which had elevated surface temperatures, in order to inform sensor placement and better understand the localised nature of heat flows occurring within the building.

\section{SENSOR POSITIONS IN ALL DWELLINGS}

In order to capture the influence of zonal and services related heat fluxes a detailed monitoring protocol was required both within and immediately adjacent to the monitored flats. Due to the occupied nature of the communal areas and control flat the sensors where predominantly located adjacent to the walls. However in the unoccupied flats ( $\mathrm{B}$ and $\mathrm{C}$ ) additional centre room readings were taken in the living rooms. By measuring both the dry bulb air temperature $\left(\breve{\Gamma}_{\mathrm{PW}}\right)$ and the globe temperature $\left(\breve{\Gamma}_{\mathrm{A}}\right)$ at seated head height $(1.1 \mathrm{~m})$ above floor level (AFL) in the centre of the living rooms and also the air temperature at ankle level $(0.1 \mathrm{~m} \mathrm{AFL)} \mathrm{it} \mathrm{was}$ possible to derive the mean radiant temperature $\left(\breve{\Gamma}_{Z}\right)$ and thereby study the influence of the direct solar radiation gains on these zones. The position of the individual sensors in relation to the floor plans of the monitored flats and adjacent corridor areas are shown in Figure 6, Figure 7 and Figure 8.

All of the flats within the development contain a Heat Interface Unit (HIU) which supplies both the heating and domestic hot water (DHW) drawn from the communal distribution system. The surface temperatures of the primary pipework supplying heating in ( $\mathrm{Htg}$ in), heating out (Htg out), cold water in (CW in) and domestic hot water (DHW) were all monitored in order to understand the patterns of heat loss.

Ventilation to individual flats is provided by decentralised Mechanical Ventilation with Heat Recovery (MVHR) systems. In order to understand how the individual systems are contributing to adding or removing excess heat from the flats probe thermistors where placed in the ductwork of each unit adjacent to the Fresh Air (FA), Exhaust (Exh), Supply (Sup) and Extract (Ext) terminals with an additional sensor placed in the Living room fresh air (FA supply) diffuser. This arrangement allowed the heat gains at critical points in the ventilation system to be monitored.

In addition to the detailed monitoring protocol within individual flats additional sensors where placed in communal corridor areas, including ceiling soffits. The monitoring of the communal areas served the aim of establishing air and surface temperature profiles within the adjacent boundary zones, in order to understanding how the core of the building was affecting heat transfer to and from the flats. The location of sensors installed in (and contiguous to) Flat A is shown in Figure 6. 


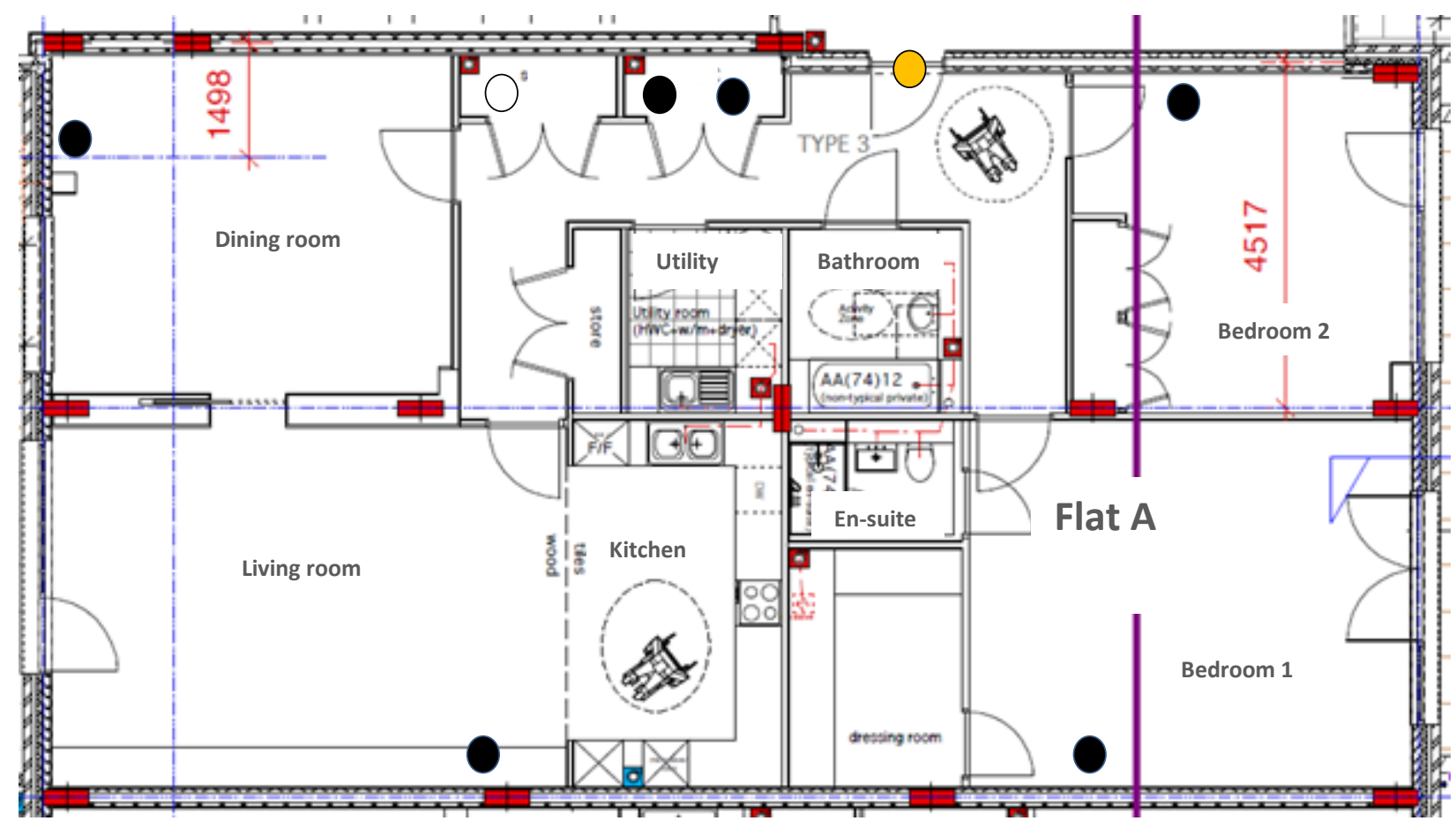

Room air temperature and relative humidity sensor

Air temperature sensors on MVHR

$\bigcirc \quad$ Pipe sensors on HIU

Corridor soffit ceiling void and heating system distribution pipes

Figure 6. Layout and sensor locations - Flat A (Control)

The location of sensors installed in Flat B are shown in Figure 7. 


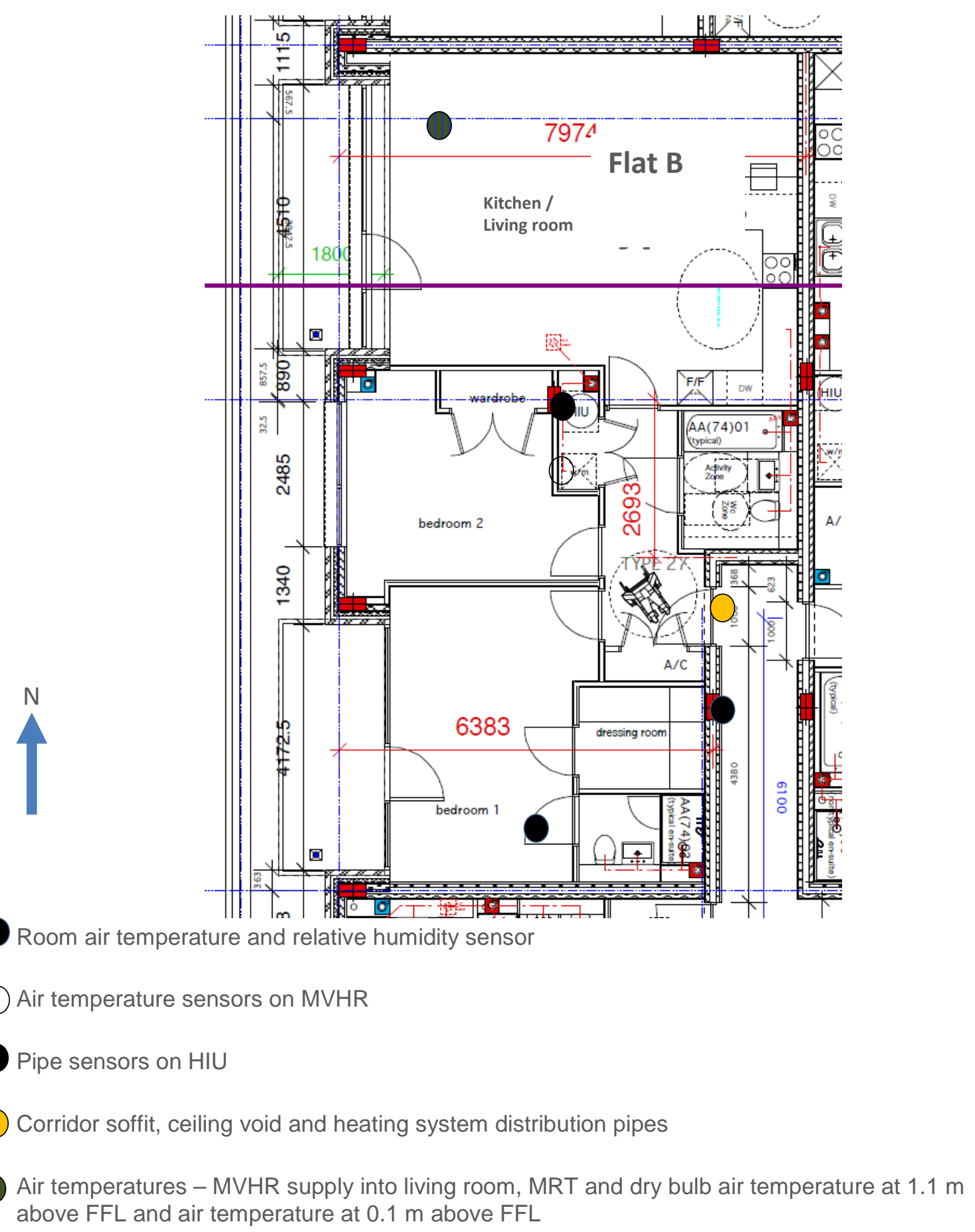

Figure 7. Layout and Location of Sensors - Flat B

The location of sensors installed in Flat $\mathrm{C}$ are shown in Figure 8. 


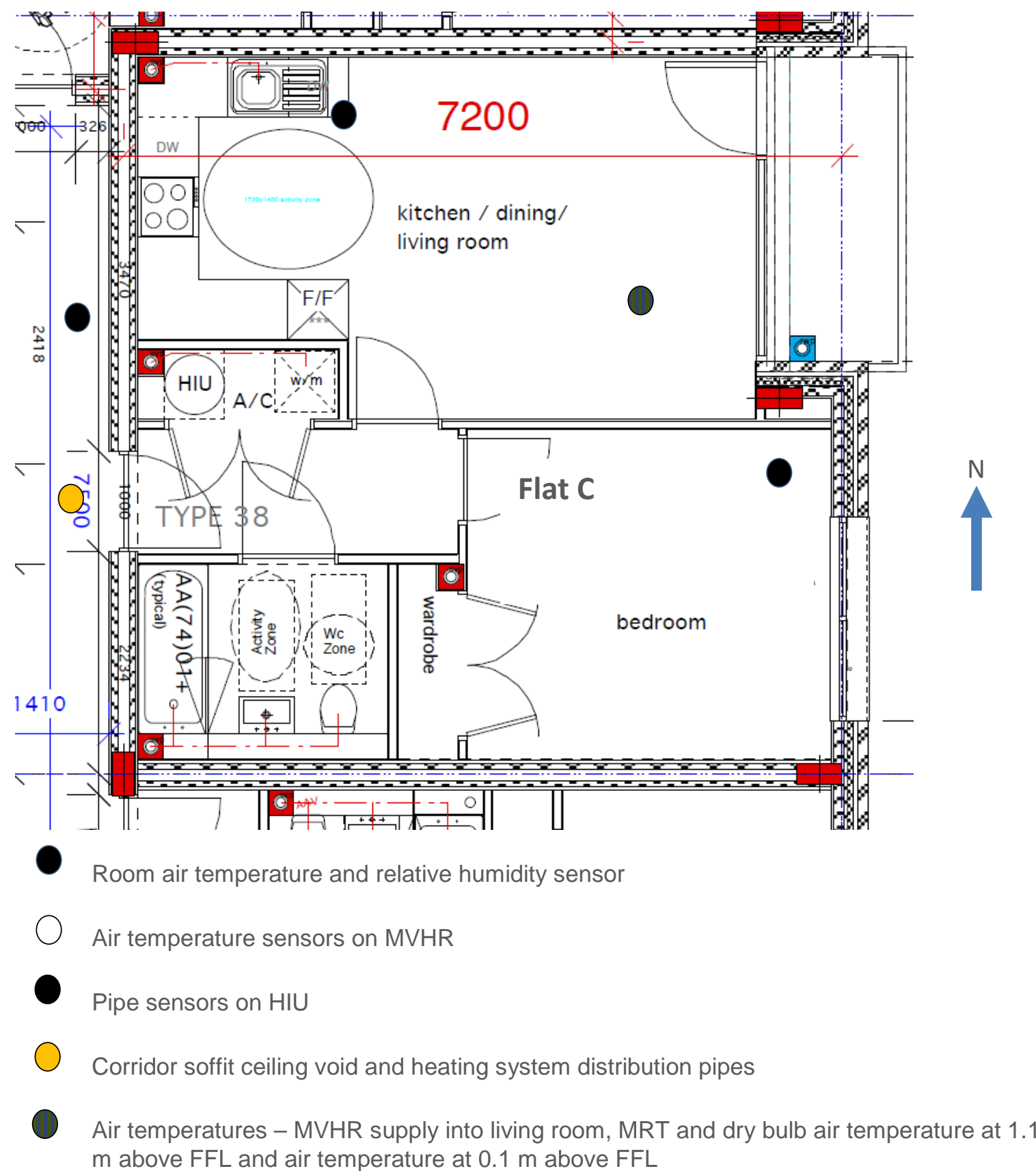

Figure 8. LAyout and location of SENSORS - FLAT C 


\subsection{Results and Analysis - Monitored temperature data}

\subsection{OCCUPIED ZONES}

Over the month long monitoring period the mean $\breve{\mathrm{T}}_{\mathrm{GCO}}$ was recorded as $11.6^{\circ} \mathrm{C}\left(\min 5.5^{\circ} \mathrm{C}, \max 21.8^{\circ} \mathrm{C}\right)$. This indicates that the monitoring took place under ambient temperature conditions which were close to the thirty year (1981-2010) mean monthly level for October $\left(11.4^{\circ} \mathrm{C}\right)$, as recorded at the nearest Met Office recording station [58].

The air temperature within the habitable rooms in Flat $\mathrm{A}$ (control) remained relatively stable across the monitoring period, dropping from a daily maximum of $24^{\circ} \mathrm{C}$ at the beginning to a fairly constant $20-21^{\circ} \mathrm{C}$ at the

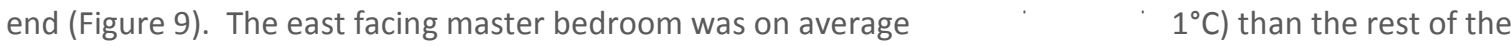
flat, particular during the period when the flat was unoccupied. This may indicate that natural ventilation (and internal shading devices) are being used to cool the flat during periods of occupancy.

\section{Air temperatures - habitable rooms (Flat A)}

\section{$\Rightarrow 1$}

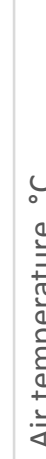

20

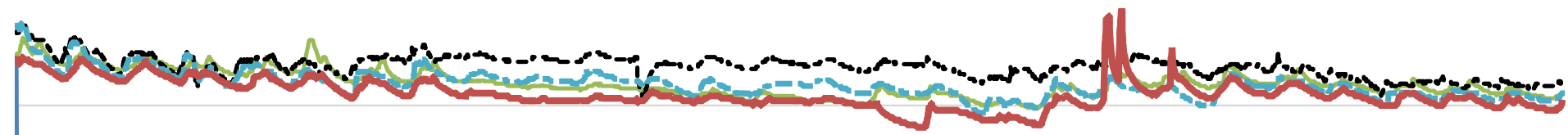

15
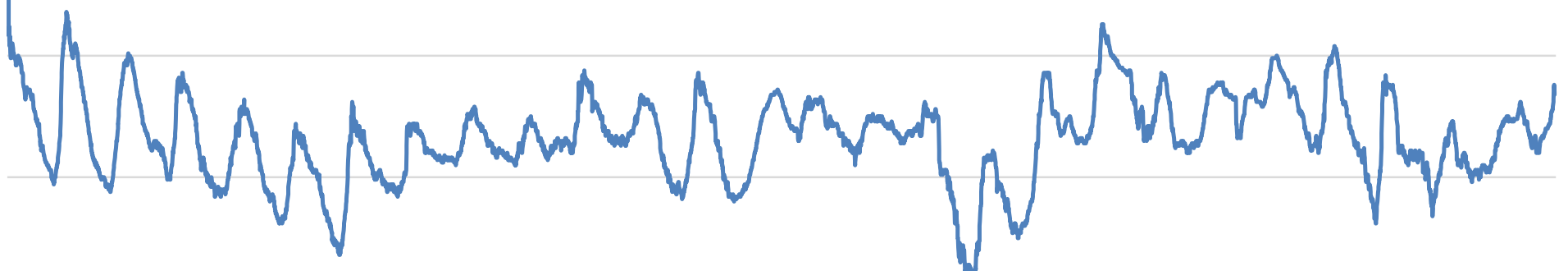

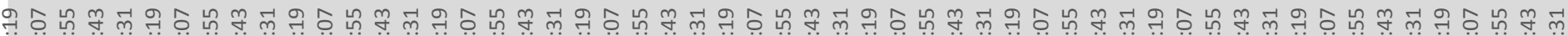
ت̇ ठ் 8/109/10 10/1011/1012/1013/1014/1015/1016/1017/1018/1019/1020/1021/1022/1023/1024/1025/1026/1027/1028/1029/1030/1031/10 1/11 2/11 3/114/11 Time and Date

\section{Figure 9. HABitable room air temperatures (Flat A - Control)}

A similar overall air temperature profile was seen in Flat $B$, with mean air temperatures dropping from approximately $25^{\circ} \mathrm{C}$ at the beginning of the monitoring period to a relatively stable $21^{\circ} \mathrm{C}$ at the end. The notable difference between Flat B and the control flat is that the recorded living room dry bulb $\left.\breve{T}_{\rho \mathrm{w}}\right)$ and globe thermometer temperatures $\left(\breve{\Gamma}_{\hat{A}}\right)$ show a pronounced daily peak in the late afternoon. During the month of October the diurnal temperature maxima is reached at around 5.15pm (approximately one hour before sunset), at the time when the solar angle is still above the surrounding buildings and the azimuth is approaching the normal subtended from the west facing glazing [59]. 
From the recorded $\breve{T}_{\rho \mathrm{W}}$ and $\breve{\mathrm{T}}_{\mathrm{g}}$ readings and an estimate of the indoor air velocity an approximation of the mean radiant temperature $\left(\breve{\Gamma}_{\mathrm{Z}}\right)$ can be calculated as described in Equation $1[60]^{1}$.

Equation 1. Mean Radiant Temperature (Iso 7726)

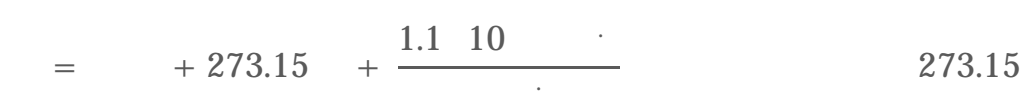

Where:

$\breve{\Gamma}_{Z}$ is the mean radiant temperature $\left[{ }^{\circ} \mathrm{C}\right]$

$\breve{\Gamma}_{\mathrm{A}}$ is the globe temperature $\left[{ }^{\circ} \mathrm{C}\right]$

$\breve{\Gamma}_{\mathrm{PW}}$ is the dry bulb air temperature $\left[{ }^{\circ} \mathrm{C}\right]$

$\mathrm{H}_{b}$ is the air velocity at the level of the globe $\left[\mathrm{ms}^{-1}\right]$

is the diameter of the globe $[\mathrm{m}]$

₹ is the emissivity of the globe [-]

The influence of direct solar radiation in the late afternoon in Flat B is likely to play a significant role in elevating the operative temperature $\left(\breve{T}_{0^{\prime}}\right)$. According to McMullen [61] when indoor air movement is low, the $\breve{\mathrm{T}}_{\mathrm{Z}}$ at the centre of the room is an acceptable proxy for the comfort temperature experienced by the room occupants, however $\breve{T}_{0^{\prime}}$ remains the most widely used indicator [10] [62] [30] . Under still indoor air conditions

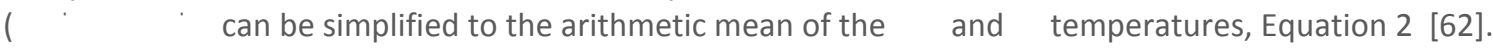

\section{Equation 2. Operative Temperature (CibSe, 2015)}

$\breve{\Gamma}_{0^{\circ}}=0.5 \breve{\Gamma}_{\rho \mathrm{W}}+0.5 \breve{\Gamma}_{\mathrm{Z}}$

The influence of late afternoon solar gains on the living room $\breve{\Gamma}_{\rho \mathrm{W}}$ and $\breve{T}_{0^{\prime}}$ can be clearly seen in Figure 10 , and are likely to have a significant impact on occupant at times when the flat is receiving high levels of direct solar radiation. Over the monitored period this was most pronounced in the late afternoon of October $2^{\text {nd }}$ where the $\breve{\Gamma}_{0^{\circ}}$ remained above $30^{\circ} \mathrm{C}$ for over 4 hours, reaching a maximum of $36.3^{\circ} \mathrm{C}$ (approximately $7.4^{\circ} \mathrm{C}$ higher than the $\left.\breve{T}_{\rho \mathrm{w}}\right)$ (Figure 10).

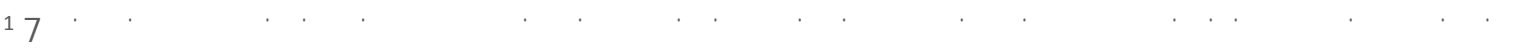
assumption that the internal air conditions were still (see CIBSE Guide A, 2015, 1.2.2). This assumption seems reasonable since all windows and doors were closed throughout the monitoring period and the thermal envelope of the building is airtight $\left(q_{50}=6.6 \mathrm{~m}^{3} / \mathrm{m}^{2} . h\right.$, see Table 1$)$. 

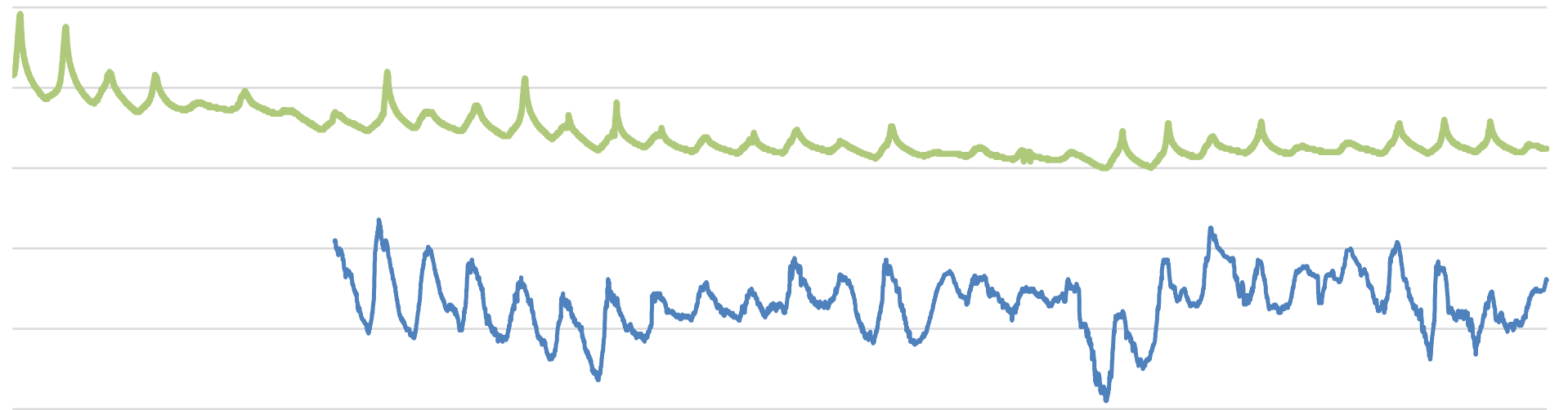

Figure 10. Habitable Room air and operative temperatures (Flat B)

A similar overall air temperature profile was seen in Flat C, with the mean $\breve{\Gamma}_{\rho \mathrm{f}}$ dropping from approximately $25^{\circ} \mathrm{C}$ at the beginning of the monitoring period to a relatively stable $21^{\circ} \mathrm{C}$ at the end. As with Flat $\mathrm{B}$ the living room $\breve{\Gamma}_{\mathrm{PW}}$ and $\breve{\Gamma}_{\mathrm{A}}$ data showed a pronounced daily peak. The daily temperature spiking occurred much earlier in the day in Flat $\mathrm{C}$ however, as might be anticipated from the east facing orientation of this flat. Over the monitoring period the $\breve{T}_{0^{\prime}}$ diurnal maxima occurred at approximately 9.20am (about two hour after sunrise) on $14^{\text {th }}$ October [59]. At this time the living room $\breve{\Gamma}_{0^{\circ}}$ reached $35.3^{\circ} \mathrm{C}$, some $8.7^{\circ} \mathrm{C}$ above the $\breve{\Gamma}_{\text {fW }}$ (Figure 11 ). 


\section{Air and operative temperatures - habitable rooms (Flat C)}

40

Outside $\longrightarrow$ Kitchen $\quad---$ Bed Rm Living $1.1 \mathrm{~m}(\mathrm{Tdb}) \quad \ldots$ Living 1.1m (Tc)

35

30

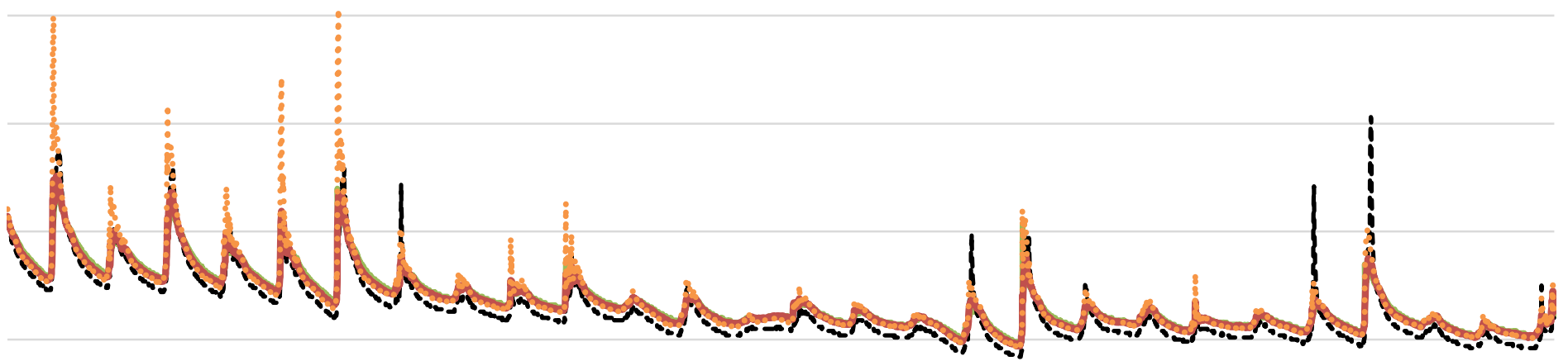

15

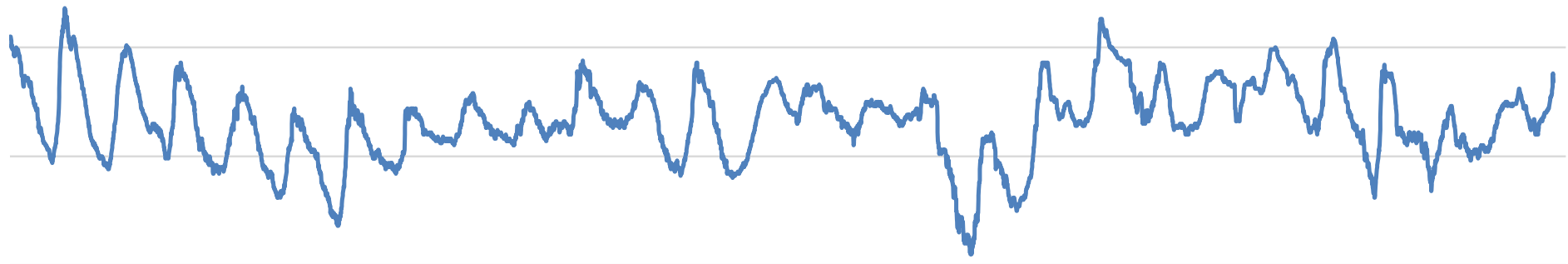

0

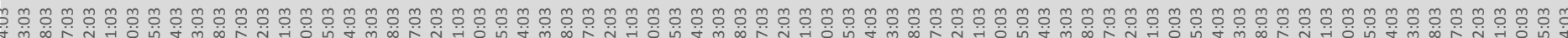

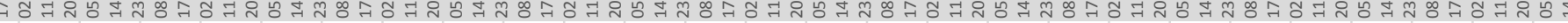

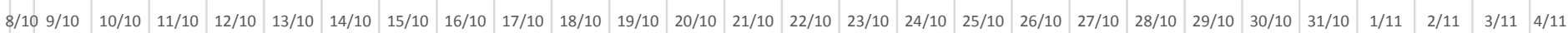
Time/Date

Figure 11. habitable room air and operative temperatures (Flat C)

\subsection{COMMUNAL AND UNOCCUPIED ZONES}

The communal corridor soffit air temperatures were consistently above $30^{\circ} \mathrm{C}$ in the case of Flat B (Figure 12) and above $27^{\circ} \mathrm{C}$ in the case of Flat C (Figure 13). The elevated corridor soffit temperatures coupled with a lack of purge ventilation possibilities in the corridor zones are the likely cause of the consistently high corridor air temperatures. In Flat B the mean corridor air temperature (recorded at $1.1 \mathrm{~m} \mathrm{AFL}$ ) across the monitoring

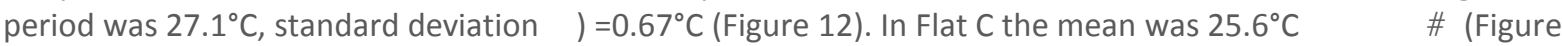
13). Since the mean internal air temperatures of the flats are lower than the respective corridor (and corridor soffit) temperatures these zones can be considered to be playing a contributory role in relation to the net heat flux into both flats. 
Corridor and ceiling void temperatures - 7 day period (Flat B)

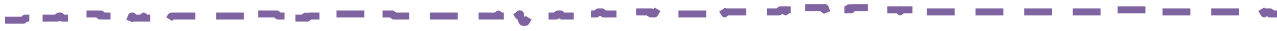

20
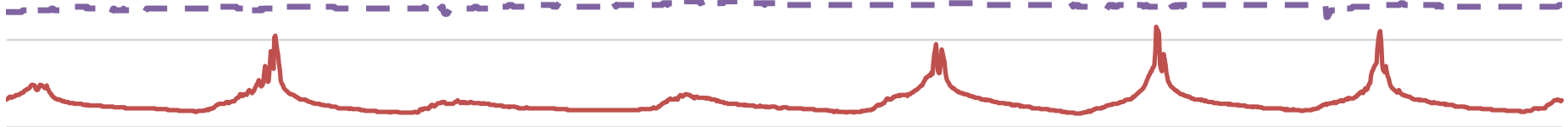

15

10
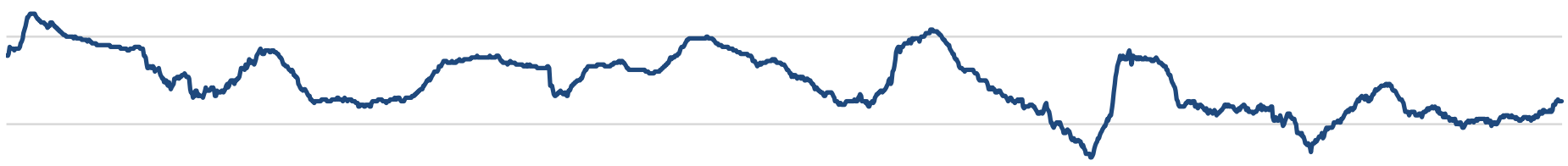

5

0

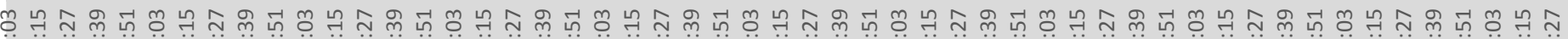

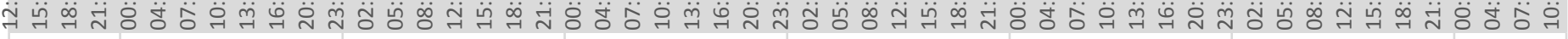




\section{Corridor and ceiling void temperatures - 7 day period (Flat C)}

Outside $=---=$ Ceiling void air $\longrightarrow$ Soffit $\quad-$ Corridor $\longrightarrow$ Living $1.1 \mathrm{mdb})$

30

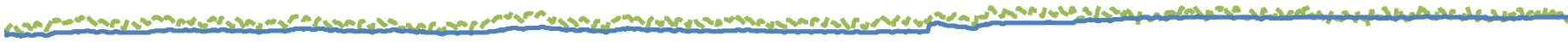

25
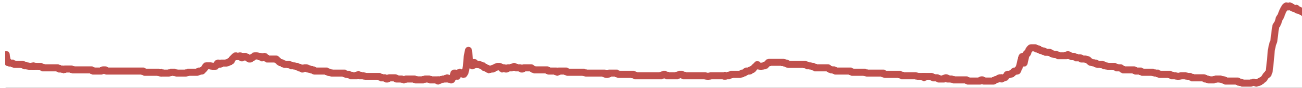

15

10

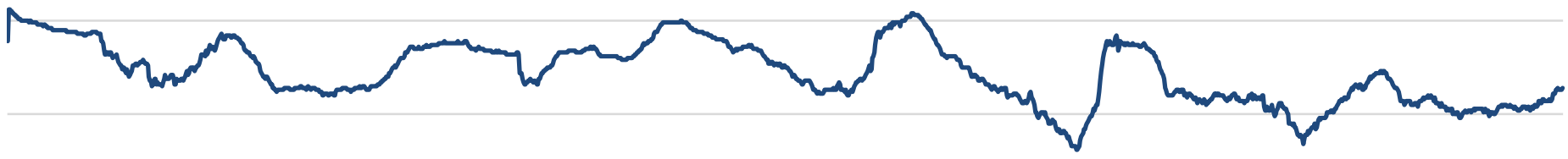

0

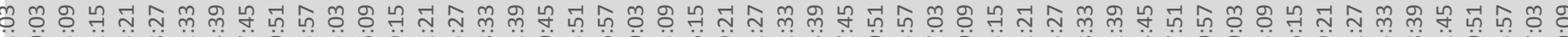

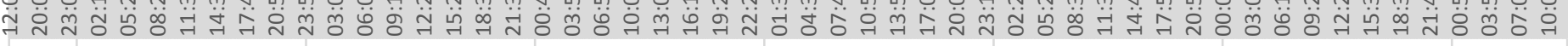
$28 / 10$

$29 / 10$

$30 / 10$

$31 / 10$

$1 / 11$

$2 / 11$

Time and Date

Figure 13. Corridor and Soffit temperatures- 7 day period (Flat C)

\subsection{BUILDING SERVICES - HIU AND DOMESTIC PIPEWORK}

As a result of the internal heat gains released from the HIU unit (and associated pipework) the air temperature in the services cupboard in Flat A remained consistently waN $\mathrm{S} N \not \$ \gamma љ 3^{\circ} \mathrm{C}$ ) than the occupied rooms (Figure 14). Although the communal heating system distribution pipes within the HIU cupboard are insulated in Flat $A$, this appears to have been carried out as a remedial measure (Figure 3). The HIU pipework in Flats B (Figure 4) and C (Figure 5) is uninsulated, although it has been painted in a low emissivity silver paint.

The surface temperature of the pipes supplying water to and from the HIU, in Flat A, remain very constant across the monitoring period $\left(\right.$ at $66^{\circ} \mathrm{C}$ ) up to the $19^{\text {th }}$ October. The pipe temperatures then drop to $63^{\circ} \mathrm{C}$ for seven days before returning to $66^{\circ} \mathrm{C}$ (Figure 14). It is clear from the domestic hot water (DHW) profile that the flat was occupied up to the $16^{\text {th }}$ October, with regular use of the DHW system. There is then a period where no DHW is drawn, suggesting no occupancy, with occupancy clearly returning from the $25^{\text {th }}$ October. The high return temperature of the primary heating system water supply suggests that flow volume regulation of the HIU is poor, with no measurable difference between flow and return temperature occurring across the HIU, even during periods of occupancy (Figure 14).

A similar overall pattern is seen with closely matched flow and return temperatures of the unoccupied flats, Flat B (Figure 15) and Flat C (Figure 16). The close correlation $\left(R^{2}=0.9975\right)$ between primary flow and return temperatures in Flat B is shown in Figure 17. Whilst the temperature and profile of the HIU pipework in Flat $C$ suggests that the HIU is in a low temperature stand-by mode, with periodic high temperature sterilisation purges (Figure 16). 


\section{Building services - surface and air temperatures (Flat A)}

80 $-\infty-\infty$ Htg in $\quad$.........Htg out CW in $\longrightarrow$ DHW Living Rm (Tdb)

- - HIU Cupbd (Tdb)

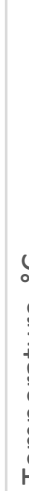

70

60

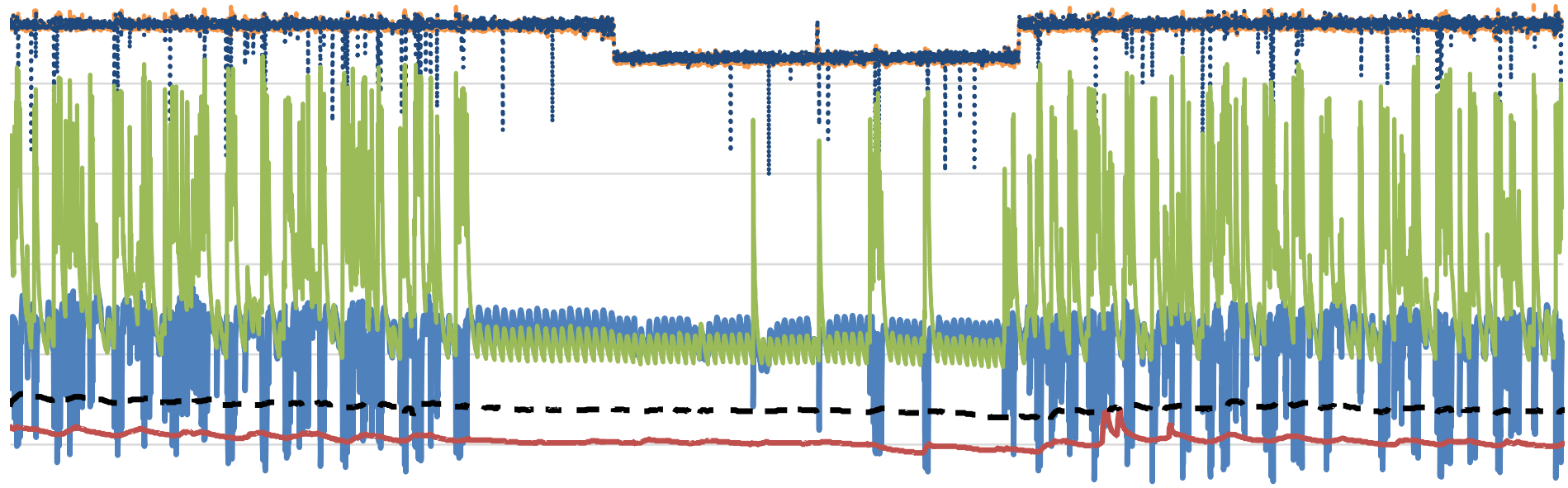

10

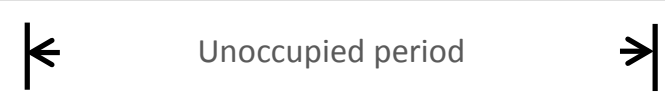

0

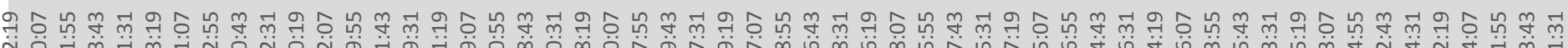

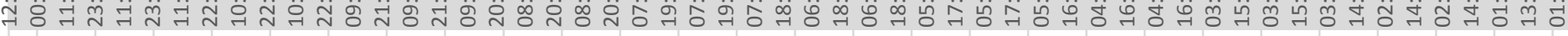
8/109/10 10/1011/1012/1013/1014/1015/1016/1017/1018/1019/1020/1021/1022/1023/1024/1025/1026/1027/1028/1029/1030/1031/10 1/11 2/11 3/114/11 Time/Date

Figure 14. Temperatures of HIU PIPEWORK AND SERVices CUPBoARd (FLAT A) 
Building services - surface and air temperatures (Flat B)

80

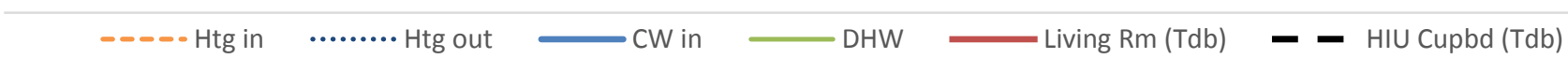

70

60

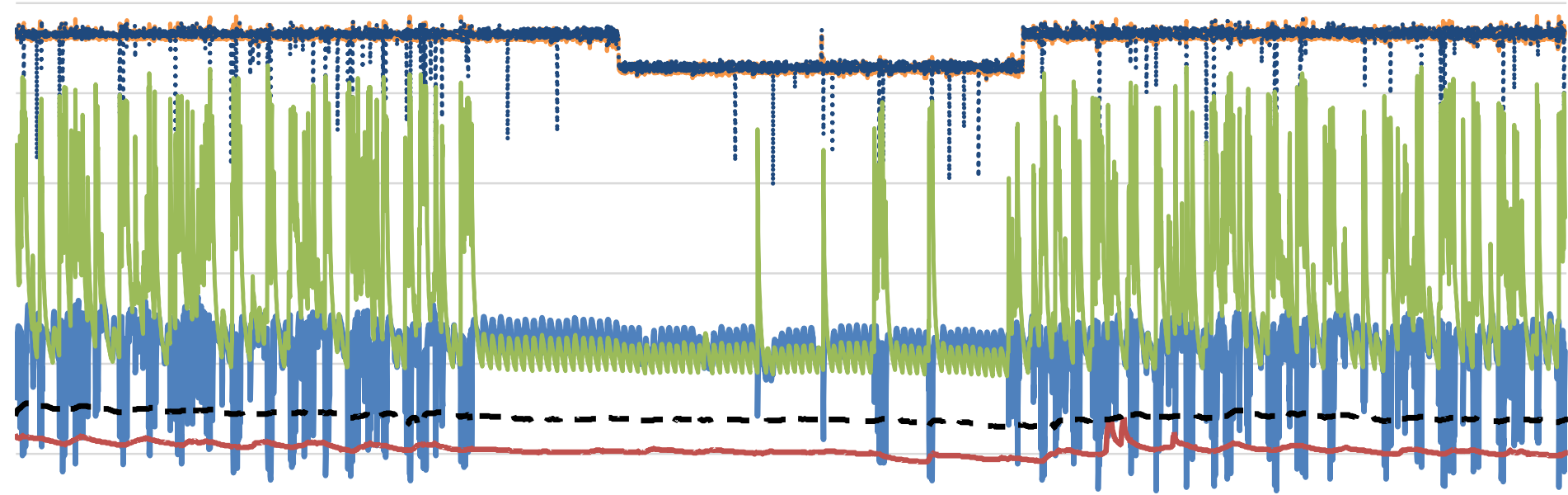

10

0

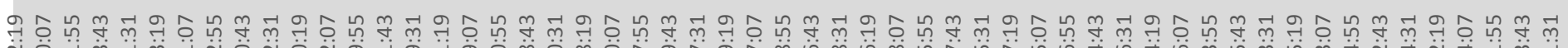

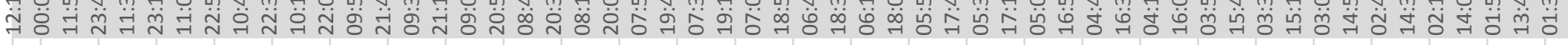
8/109/10 10/1011/1012/1013/1014/1015/1016/1017/1018/1019/1020/1021/1022/1023/1024/1025/1026/1027/1028/1029/1030/1031/10 1/11 2/11 3/114/11 Time/Date

Figure 15. Temperatures OF HIU PIPEWORK AND SERVICES CUPBoARd (FLAT B) 


\section{Building services - surface and air temperatures (Flat C)}

70

$-=--=H$ tg in $\quad \cdots . . . . . . H$ tg out $\longrightarrow$ CW in $\longrightarrow$ DHW

60

50

40

30

20

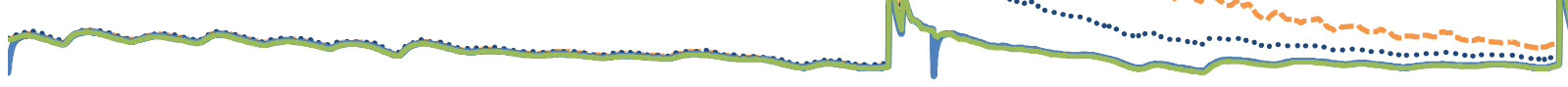

10

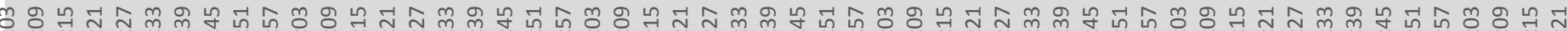

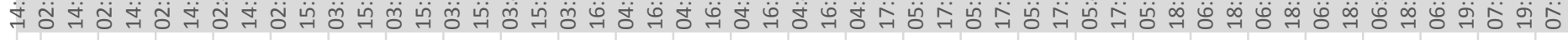
8/109/10 10/1011/1012/1013/1014/1015/1016/1017/1018/1019/1020/1021/1022/1023/1024/1025/1026/1027/1028/1029/1030/1031/10 1/11 2/11 3/114/11 Time/Date

Figure 16. Temperatures of HIU Pipework ANd Services Cupboard (Flat C) 


\section{HIU inlet and outlet temperatures (Flat B)}

70

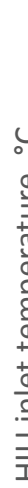

65

60

55

50

45

$R^{2}=0.9975$

0

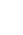

50

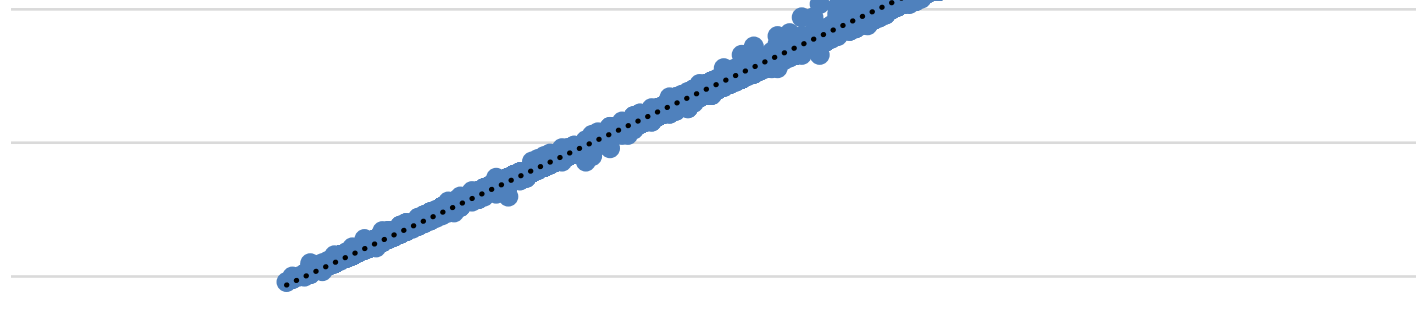

40

40

45

50

55

60

65

HIU outlet temperature ${ }^{\circ} \mathrm{C}$

Figure 17. Comparison OF heating SyStem inLet AND OUtLet temperatures (FLAT B)

Monitoring of the temperatures of the cold water (CW) feed to the HIU (Flat A) show that it remains at or above $30^{\circ} \mathrm{C}$ for prolonged periods of time (mean $31.7^{\circ} \mathrm{C}, \quad=3.48^{\circ} \mathrm{C}$ ), only dropping to $20^{\circ} \mathrm{C}$ during periods of significant water draw (Figure 14). A similar pattern of elevated CW inlet temperatures is seen in Flat B (Figure 15) where the mean $\mathrm{CW}$ feed in temperature is $36.5^{\circ} \mathrm{C}\left({ }^{\prime}=0.7^{\circ} \mathrm{C}\right)$. In Flat $\mathrm{C}$ the $\mathrm{CW}$ feed in temperature is much lower at $23.9 \mathrm{C}\left({ }^{\prime}=1.7^{\circ} \mathrm{C}\right)$, possibly as a result of the HIU system being in stand-by mode. The variance in CW feed in temperatures across different zones of the building suggests that the mains CW supply is absorbing substantial heat gains from localised areas of the building core (or nearby high temperature pipework) enroute to each flat (as discussed in section 3.2).

\subsection{BUILDING SERVICES - MVHR SYSTEM}

Across the monitoring period the MVHR unit in Flat $A$ is predominately operating in summer bypass mode with

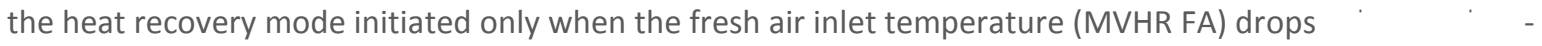
$14^{\circ} \mathrm{C}$ (Figure 18). By alternating between these two modes the MVHR unit is able to maintain a relatively constant internal temperature in the living room ( on the MVHR supply air temperatures. It can be seen (Figure 18) that during periods of high DHW use the supply air temperature increases $\bar{D} e$ èdzJíz $Y 2^{\circ} \mathrm{C}$ ) within a very short time step to close to the temperature of the extract air. Since the MVHR extract temperature is virtually constant (Figure 18) this suggests that there is significant latent heat exchange occurring within the MVHR unit at times of high DHW consumption (e.g. showering/bathing). 


\section{MVHR and DHW temperatures - 7 day period (Flat A)}



70
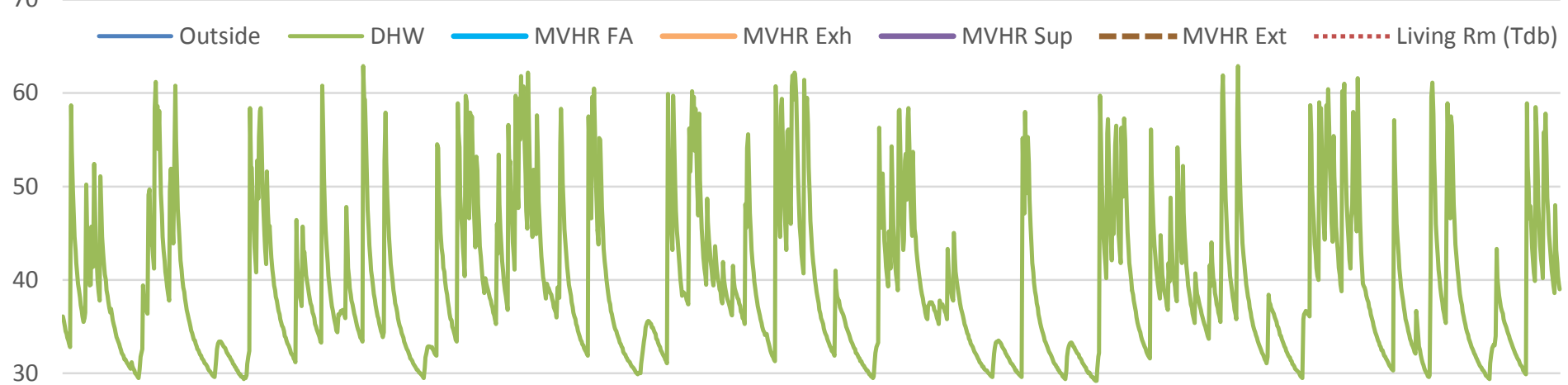

20

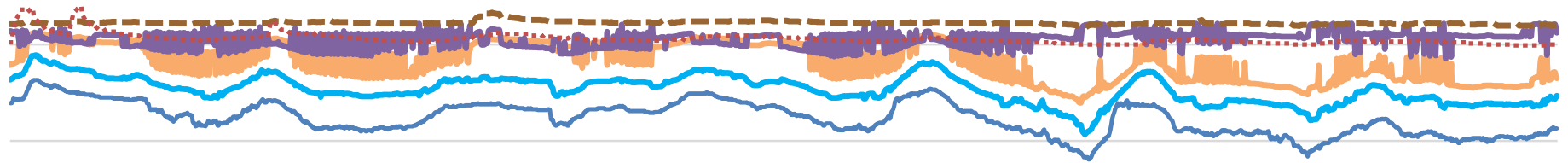

0

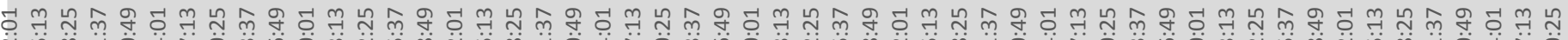

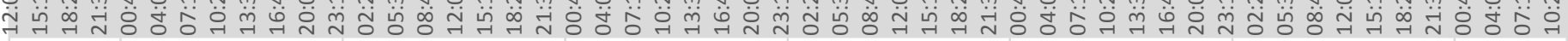
$28 / 10$ $29 / 10$ $30 / 10$ $31 / 10$ $1 / 11$ $2 / 11$

Figure 18. MVHR AND DHW TEMPERATURES OVER A 7 DAY PERIOD - SHOWING INFLUENCE OF DHW DRAW-OFF ON SUPPLY AIR temperature (FLAt A)

Due to the elevated extract air temperatures in Flat B (Figure 19) and C (Figure 20) the MVHR units remain in summer bypass mode throughout the monitoring period. Remarkably the living room fresh air supply (living FA Sup) temperature never drops below $20^{\circ} \mathrm{C}$ in Flat B and $19.75^{\circ} \mathrm{C}$ in Flat $\mathrm{C}$, despite external temperatures dropping below $10^{\circ} \mathrm{C}$ at times. 


\section{MVHR temperatures - 7 day period (Flat B)}

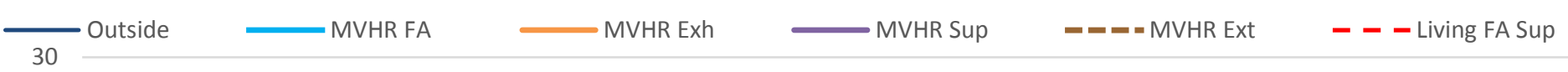

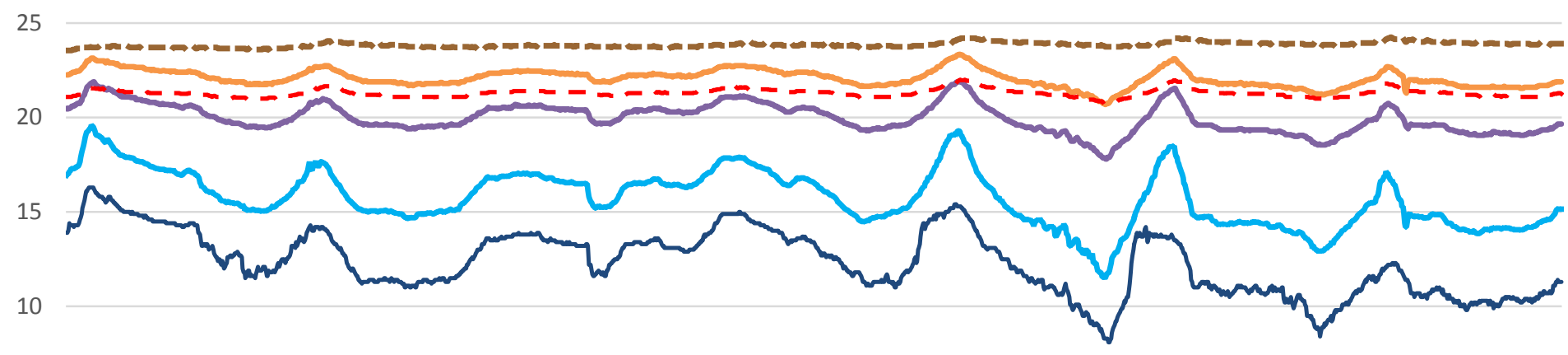

0

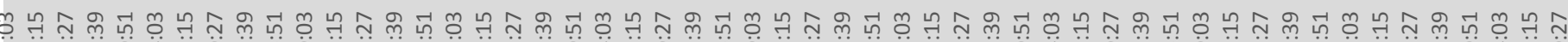

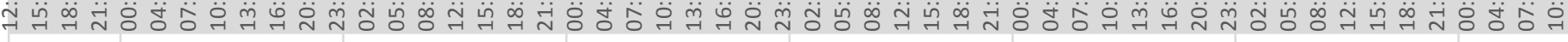
$28 / 10$ $29 / 10$ $30 / 10$ $31 / 10$ $1 / 11$ $2 / 11$ $3 / 11$ Time and Date

Figure 19. MVHR AND LiVING ROOM SUPPLy AIR TEMPERATURES OVER A 7 DAY PERIOd (FLAT B)

\section{MVHR temperatures - 7 day period (Flat C)}

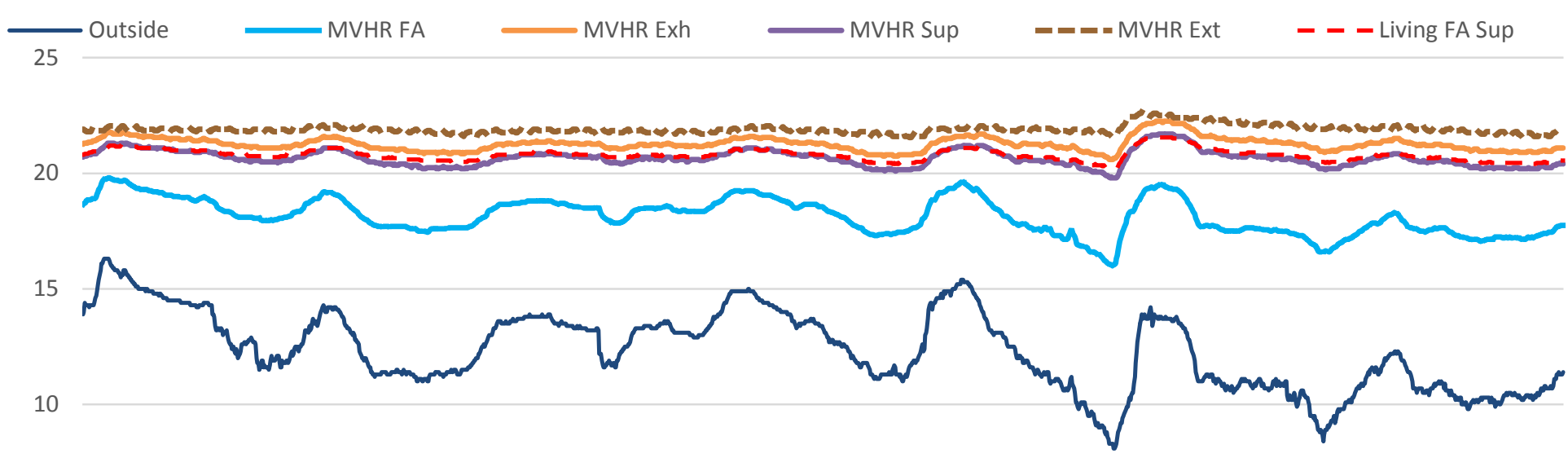

5

0

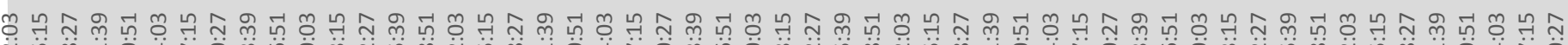

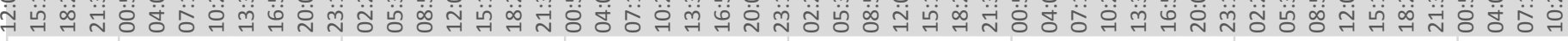
$28 / 10$
$29 / 10$
$30 / 10$
$31 / 10$
$1 / 11$
$2 / 11$
$3 / 11$
Time and Date 
In all of the flats significant warming of the outside air takes place before it arrives at the MVHR. On average (in Flat A) the fresh air entering the MVHR unit is $3.3^{\circ} \mathrm{C}$ warmer than the outside air (Figure 18). This suggests that the insulation of the intake ducts within the ceiling void is ineffective (or missing) and that the MVHR unit is sited too far from the external air intake and exhaust terminals.

Even in summer bypass mode further warming of the fresh incoming air occurs as the air passes through the MVHR unit (as shown by the difference in temperatures between the MVHR FA sensor and the MVHR Sup sensor). Further heat gains are then picked up by the supply air as it passes through the distribution ductwork from the MVHR supply terminal to the living room diffuser (Living FA Sup). This later stage of internal heat gain is most pronounced in the case of Flat B (Figure 19). The net result of this process is that the outside air is warmed by up to $2-4 \complement_{C}$ before it enters the MVHR unit. The air then recovers a further 2-6 $\complement_{C}$ as it passes through the MVHR. When the air then enters the living room it is $2-3 \subseteq \mathcal{C}$ warmer again, as illustrated in Figure 21.

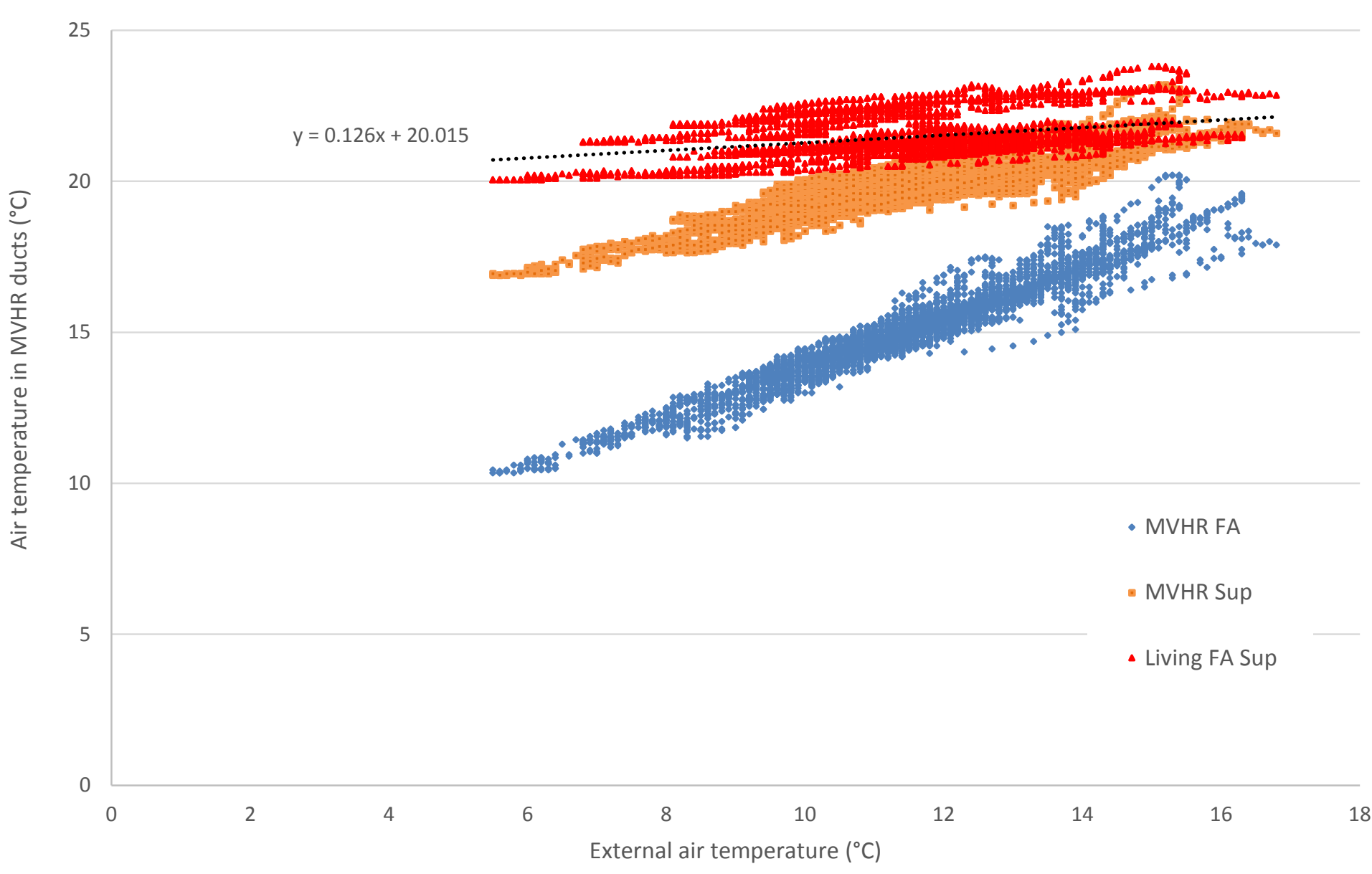

Figure 21. Comparison OF EXTERNAL AIR AND MVHR SUPPLy AIR TEMPERATURES - SHOWING CUMULATIVE INFLUENCE OF HEAT GAINS (FLAT B)

Based on a linear regression the relationship between the external air temperature $\left(\breve{\Gamma}_{G}\right)$ and the mean living

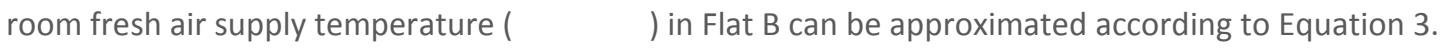

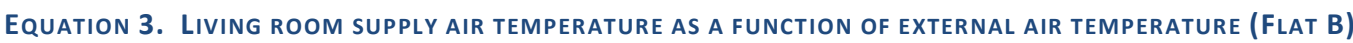

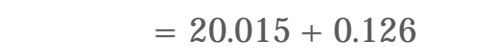

A similar pattern of ventilation heat gains can be seen in Flat C (Figure 22), although the proportion of the heat gains occurring between the MVHR unit and the living room diffuser is smaller than in Flat B. 


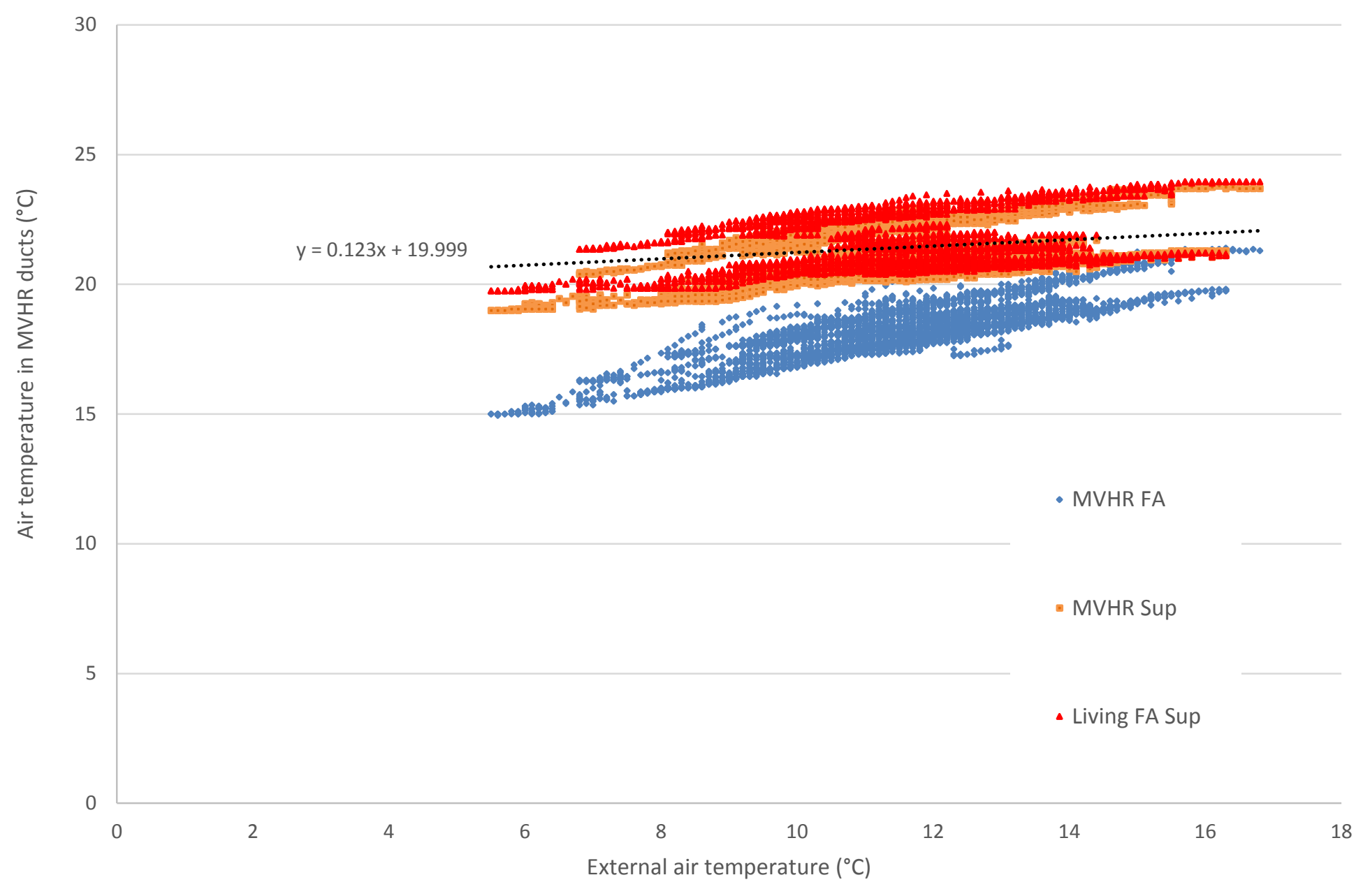

Figure 22. Comparison of outside air AND MVHR supply air temperatures - showing cumulative heat gains (Flat C)

Applying a linear regression the relationship between the external air temperature $\left(\breve{\Gamma}_{\text {Gvo }}\right)$ and the mean living

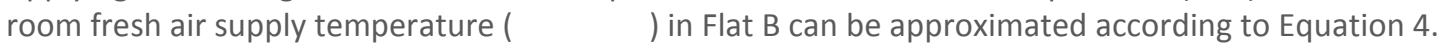

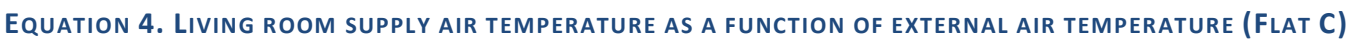

$\breve{\mathrm{T}}_{\text {бУ ๆТ } \Omega \Omega X^{\circ}}=19.999+0.123 \breve{\Gamma}_{\text {GVO }}$

From Equation 3 and Equation 4 it can be seen that (on average) even when the external air temperature is as low as $6^{\circ} \mathrm{C}$ any cooling benefit from the mechanical ventilation system is lost as a result of the cumulative heat gains absorbed en-route to the point of delivery.

\subsection{Discussion}

\subsection{DISCUSSION OF MONITORED DATA}

Detailed monitoring of three different flats, and their adjacent communal areas, over a period of cool autumnal weather (when the level of solar gains was relatively low) provided a valuable insight into the typical thermal performance of these sections of the building. 


\subsection{DISCUSSION OF MONITORED DATA - FLAT A}

Flat A, which was intermittently occupied during the monitoring period, served as a useful control study due to its double sided aspect and ground floor location. Despite complaints from the occupants that the flat was consistently too warm, temperature data for the individual rooms showed that the flat was not overheating

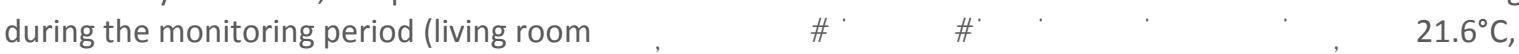

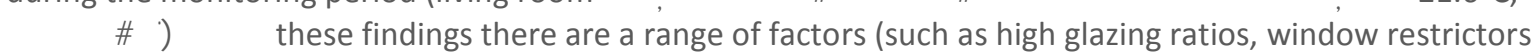
and a lack of external shading devices) that indicate that during a period of warm weather the flat may be difficult to thermally regulate.

There were no sources of heat gain identified within the flat that would cause significant overheating in isolation. However, the apparent lack of control of the HIU flow and return temperature suggest that the HIU has not been properly commissioned. The heat gains from the heating system distribution pipes passing through the ceiling void and into the HIU cupboard are resulting in increased heat gains to this space.

Detailed monitoring of the MVHR system provided a clear insight into how the mechanical ventilation system in the flat is operating. The basic thermal efficiency of the MVHR unit in heat recovery mode is around $85 \%$, however the percentage of heat recovered whilst the unit was in summer by-pass mode remained above $50 \%$. This heat recovery rate is based on the MVHR fresh air inlet temperature (measured at the terminal), however the actual level of heat recovery from the complete system (based on the internal to external air temperature difference) is significantly greater ( $\mathrm{Y} 60 \%$ based on mean monitored data). This means that for ambient

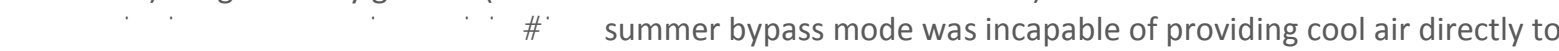
the habitable rooms.

Of possibly greater significance to avoiding overheating and achieving good thermal control in Flat $A$ is the means of achieving heat rejection. The design of the opening lights with the intention to meet Approved Document F of the UK Building Regulations is based solely on the need for purge ventilation (i.e. intermittent removal of pollutants) [63]. The need to achieve high levels of ventilation to remove heat gains in warm weather has largely been ignored. The provision of patio doors only in both bedrooms (in this ground floor flat) means that there is no secure means of purging excess heat.

The lack of effective purge ventilation possibilities were not identified during the Standard Assessment Procedure (SAP) assessment of Flat A wherein the SAP assessor has estimated that the effective air change rate (during hot weather) is ' 3 ach - (Windows open half the time)'. This value can only be derived using SAP (2009) Table P1, on the basis of a single story dwelling where cross ventilation is possible and windows can be left fully open for half the time [64]. Although it is technically possible to cross ventilate Flat A in this way, to do so would require the removal of safety restrictors on all of the opening lights and the occupant's willingness to leave them fully open for 12 hours a day. The security implications of such a strategy in the context of an urban ground floor flat render this strategy unfeasible. Statutory and ancillary overheating risk assessments can only be relied upon if they reflect such practical and contextual limitations.

\subsection{Discussion of MONITORED TEMPERATURE DATA - FLAT B}

Monitoring Flat B over a period of autumnal weather whilst the flat was unoccupied allowed a good understanding of the thermal performance of this zone of the building. In Flat B the $\breve{\Gamma}_{\rho W, \Theta ~ G l t r}$ temperatures

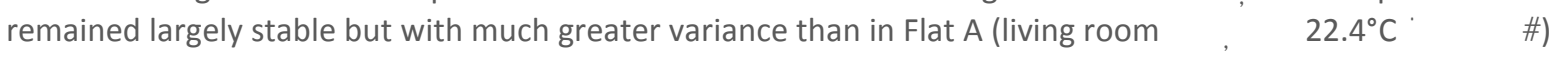
across the monitored period. Although these temperatures are not excessively warm, the lack of any occupancy gains, and the relatively cool outside air temperatures and low solar gains suggest that there is potential for periods of significantly higher internal temperatures during the warmer months.

Calculations derived from the globe temperature sensor recordings in the living room showed that at times late afternoon solar gains greatly influenced the $\breve{\Gamma}_{0^{\circ}}$ in the west facing living room $\breve{\Gamma}_{0^{\circ}, \Theta}, w_{3} 36.7^{\circ} \mathrm{C}$,

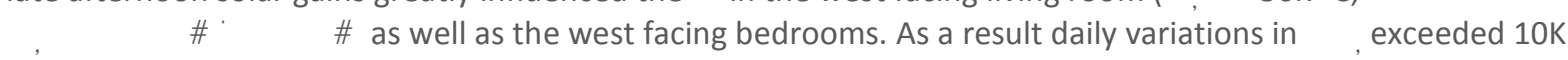
on several occasions over the monitoring period. These finding highlight the need to consider the temporal profile of operative temperatures when assessing overheating risks in highly glazed dwellings. 
Poor control of the HIU, resulted in the flow and return pipes remaining hot even in the absence of demand. Furthermore the installation of the MVHR and the HIU within the same cupboard, is resulting in significant heat gains to the MVHR unit. Lack of insulation on the primary heating and DHW pipes in the HIU cupboard has resulted in increased heat gains to this space as well as to ventilation ductwork located within the soffits. Localised heating of the ceiling in the hall from the front door to the HIU cupboard indicates that the primary heating pipework insulation is largely ineffective or missing (Figure 12).

Monitoring the MVHR closely provided a very clear insight into how this aspect of the flat is operating. Although the MVHR remained in summer by-pass mode throughout the monitoring period the level of heat recovery remained at around $45 \%$ based on the MVHR inlet and outlet air temperatures. When net gains based on the outside air temperature were considered, the net heat recovery efficiency (in bypass mode) approached $70 \%$. The impact of this means that the MVHR system is providing continual heating to the flat throughout the year.

In addition to the heat gains from the HIU and MVHR, it is anticipated that the level of solar gains to this flat (where approximately $90 \%$ of the external wall area is glazed) will be very high in summer. The combination of significant internal heat gains and high solar gains late in the day requires an effective means of rejecting the heat build-up, if the temperatures in the flat are not to become excessively hot for prolonged periods. This is of critical importance for west facing bedrooms since sleep impairment is known to markedly increase when bedroom temperatures exceed $24^{\circ} \mathrm{C}[65]$.

The specification of full height patio doors only in both the main bedroom and the living room means that to achieve effective purge ventilation both these door need to be fully open. This fact is reflected in the SAP assessment of the risk of overheating where the SAP assessor has stated that the 'Ventilation rate during hot weather (ach): 4 (Windows fully open). Using SAP (2009) Table P1, this is based on a single story dwelling where cross ventilation is not possible but the windows are open to achieve purge ventilation rates 24 hours a day [64]. Whilst it is technically possible to leave the external balcony doors open 24 hours a day, it is not practical to expect residents to sleep with external doors to the bedroom and living room fully open all night in an urban context. The SAP assessment of the risk of overheating concludes the risk to be 'Medium'. If the true ability to achieve purge ventilation was taken into account this risk rating would undoubtedly be much higher.

The impact of the lack of windows (or vents) which can be left fully open during the day and/or night, coupled with a lack of effective external shading devices, means that in summer (when external temperatures and solar gains are high) Flat B is likely to become excessively hot. Even under the late autumnal conditions monitored in this study, with no occupant gains, the flat could be considered to be unacceptably warm for prolonged periods of time.

\subsection{DISCUSSION OF MONITORED DATA - FLAT C}

Room air temperatures remained largely stable over the monitoring period in Flat $\mathrm{C}$ but with greater variance

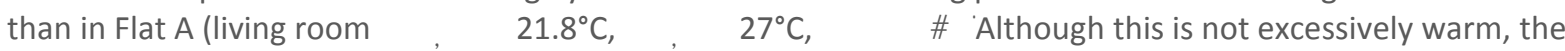
lack of any occupancy gains, and the relatively cool outside air temperatures and low solar gains suggest that there is potential for periods of significantly higher internal temperatures.

Notably there were periods when direct solar gains to the east façade of the building exerted a pronounced impact on both the $\breve{\Gamma}_{\rho W}$ and $\breve{T}_{0^{\prime}}$ within the flat. $A \breve{T}_{0^{\prime}, \Theta \text { b w }}$ of $35.3^{\circ} \mathrm{C}$, was reached at $9.20 \mathrm{am}$ on the $14^{\text {th }}$ October, and daily variations in $\breve{I}_{0^{\circ}}$, exceeded $10 \mathrm{~K}$ on several occasions over the monitoring period. The duration of

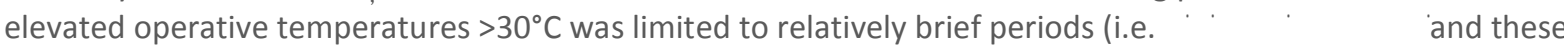
did not impact on late afternoon and evening temperatures.

Surface temperature data from the primary pipes serving the HIU indicated that there was no heating or DHW demand across the monitoring period. Unlike Flat B it was evident that the HIU was not operating in 'keep warm' mode for most of the period. There were two occasions when the HIU did receive hot water from the communal heating system, but the monitored temperature data does not indicate that there was any control function being used to maintain the HIU at a given temperature. It is therefore concluded that for the majority 
of the monitoring period there were no heat gains to the flat from the HIU or the associated flow and return pipes through the ceiling voids of this flat.

The temperature data of the air in the ducts entering and leaving the MVHR unit indicates that throughout the monitoring period the MVHR remained in summer by-pass mode. Despite operating in bypass mode the level of heat recovery remained at around 50\% (based on the inlet and outlet air temperatures), and approached $80 \%$ when the net gains (in respect of the outside air temperature) are considered. It is notable that these levels of heat gain to the outside air occurred when the HIU was off. Since the HIU and the MVHR are located in the same cupboard the ventilation system gains are anticipated to be worse when the flat is occupied and the HIU operational. The impact of such high heat gains means that the MVHR contributes to heating the flat throughout the year.

Since Flat $\mathrm{C}$ was unoccupied and the internal doors were left open during the monitoring period it suggests that the heat gains absorbed by the extracted air occurred after the air had been drawn from the wet rooms (i.e. as a result of elevated temperatures within the ceiling void). However since there was no hot water supply to the HIU for most of the monitoring period the heat gains within the ceiling void cannot be a result of the distribution pipes serving this flat. This suggests that the elevated temperature of the reinforced concrete core (of the building floor plate) may be playing a dominant role in elevating the soffit temperatures in this Flat.

In addition to the heat gains from the building services, the level of solar gains to Flat $\mathrm{C}$ (where both the living and bedrooms face east and have around $90 \%$ of the external wall glazed) are likely to be very high in summer. As was noted in the discussion regarding Flat $B$, the need to achieve high levels of ventilation to remove excessive heat gains in warm weather has largely been ignored. This fact is reflected in the SAP assessment of the risk of overheating where the SAP assessor has stated that the 'Ventilation rate during hot weather (ach): 4 (Windows fully open). According to SAP (2009, Table P1) this calculation is based on a single story dwelling where cross ventilation is not possible but the windows are left fully open to achieve purge ventilation rates 24 hours a day [64]. Whilst it is technically possible to leave the living room door and bedroom window wide open 24 hours a day, this cannot be considered an effective solution in the context of a flat which directly overlooks a busy thoroughfare. The infeasibility of such a ventilation strategy means that in summer the flat is likely to become excessively hot for prolonged periods.

\subsection{DISCUSSION OF MONITORED DATA - CORRIDORS}

The temperature data from the ceiling voids outside the monitored flats shows how stable the temperature of the structural slab and the ceiling void remained. The continually elevated temperatures of these spaces indicates that there was no effective means of cooling the core of the building. As a result the heat from the ceiling voids was warming the ceiling of the corridors and this caused the corridors to remain warm. The lack of any variation in the corridor air temperatures outside Flats $\mathrm{B}$ and $\mathrm{C}$ also indicates that there was no effective ventilation occurring in these spaces. Use of Automatic Opening Vents (AOVs) for heat purge ventilation in corridor areas could help to improve temperatures in these zones, however extensive fire safety compartmentalisation of the corridor areas is likely to limit the overall efficacy of such a strategy.

Under visual and IR inspection the insulation of the pipes within the ceiling voids was generally good, however there were localised areas where the insulation was missing (for example where distribution pipes pass through walls the insulation stops short of the fire seal, leaving lengths of exposed pipe). The continuity and long term performance of the insulation to high temperature pipework is critical to minimising the heating of the ceiling voids. Reducing communal pipework return temperatures (through improved flow regulation to the HIUs) would also have a proportionate impact on the heat gains in the communal areas.

\subsection{CONCLUSIONS}

This study has investigated the phenomenon of chronic overheating in a modern high density low carbon residential complex in North London. The building is typical of many high density developments which are currently being built across Greater London, in that it is built to a relatively high thermal performance standard and uses low carbon building services strategies (communal heating and MVHR systems). Through a detailed 
sub-hourly monitoring regime of three flats and their adjacent corridors, it was possible to evaluate the extent and causes of chronic overheating in three distinct zones of the building, and to infer the likelihood of further seasonal overheating occurring.

The monitoring identified chronic overheating risks in both of the unoccupied flats ( $\mathrm{B}$ and $\mathrm{C}$ ) as well as continuous overheating in their contiguous communal corridors areas. Despite occupant complaints of overheating in the ground floor flat A (monitored here as a control) no significant evidence of overheating was identified, although a number of risk factors were noted.

Due to the absence of effective purge ventilation possibilities throughout the entire building it seems highly likely that, when occupied, many of the single sided flats in the building would be at risk of both seasonal and chronic overheating. The primary causes of overheating can be attributed to ineffective design detailing including restricted window openings and a lack of effective external shading devices. These fundamental design limitations are exacerbated by poorly integrated M\&E services design. Ineffective insulation of pipework and ductwork together with poorly located HIU and MVHR units were found to be contributing substantial unnecessary heat gains. Even when operating in summer bypass mode (and with external air temperatures below $10^{\circ} \mathrm{C}$ ) the MVHR systems were unable to provide any cooling benefit to the dwellings.

Communal access corridors suffered from chronic overheating and an IR survey identified that this became more pronounced at higher floor levels. More effective use of ventilated soffits, internal smoke shafts and/or Automatic Opening Vents (AOVs) could have reduced the extent of overheating in these zones.

From a mechanical design perspective the concept of distributing communal heating and DHW within the fabric of a highly insulated 'low carbon' building poses a real challenge. Compact distribution runs, minimisation of flow and return temperatures and continuous effective insulation of hot water pipe runs would greatly reduce unwanted heat gains. To reduce distribution pipework losses individual HIU units should be located as close to the primary circulation branches as possible (or positioned in communal areas) and with pipework insulated in accordance with current codes of best practice [66] [66]. Thermal separation between the HIU and MVHR unit cupboards would help to reduce the high levels of unwanted heat gains occurring in summer bypass mode. Locating the MVHR units adjacent to external walls and insulating intake, exhaust and supply duct runs in accordance with current codes of practice [67] would also greatly increase the cooling potential of the ventilation systems in summer bypass mode. Since the design and installation of domestic MVHR systems is a relatively new concept for UK MEP engineers, familiarisation with European advanced practice design guidance contained in the Passivhaus standard [68] could greatly improve system performance.

Although a simplified overheating risk assessment is an integral part of the SAP procedure [64], it is critical that SAP assessors and design teams realise that such predictions are only valid when the methodology is correctly applied. In complex building typologies which are inherently vulnerable to overheating (i.e. single sided, high internal and solar heat gains, urban context) a simplified steady state model such as SAP is likely to be an unreliable method of validating design performance. Furthermore SAP calculations are often undertaken only during the final stages of the design process when major design changes are no longer feasible. Far more rigorous analysis of the overheating risk potential of all new developments is required. At the early design stage simplified methods such as the Home Quality Mark (HQM) High Temperature Tool [69] should be adopted to gain an initial understanding of how the building is likely to perform against current and future weather years. This information should be further enhanced by detailed dynamic simulation in accordance with thermal modelling guidance in CIBSE AM11 [69] and climate change scenario guidance in CIBSE TM48 [70] at the detailed design stage.

Taking all of these disparate environmental and social factors into account it seems plausible that the growing phenomenon of 'chronic' overheating in newly built urban developments in London may be a consequence of compounding policy drivers coupled with poor design integration. Without greater awareness and engagement between architects, MEP engineers, building control and planning policy makers chronic overheating may become the Achilles heel of modern 'low carbon' design. 


\section{ACKNOWLEDGEMENTS}

This work was supported by the BRE Trust as part of the 'Resilience - tackling overheating in urban dwellings' project proposal.

\section{REFERENCES}

[1] T. Larsen and R. Jensen, 'Comparison of measured and calculated values for the indoor environment in one of the first Danish Passive houses.', in Proceedings of Building Simulation 2011: 12th Conference of International Building Performance Simulation Association, Sydney, Australia, 2011.

[2] NHBC, 'PUB NF 46 Overheating in new homes - a review of the evidence, NHBC Foundation - Publication Index | NBS', 2012. [Online]. Available:

http://www.thenbs.com/PublicationIndex/Documents/Details?Pub=NHBCFOUNDATION\&Docld=302468 . [Accessed: 24-Feb-2016].

[3] DCLG, 'Investigation into Overheating in Homes: Literature Review - 2185850.pdf', Jul-2012. [Online]. Available: https://www.gov.uk/government/uploads/system/uploads/attachment_data/file/7604/2185850.pdf. [Accessed: 24-Feb-2016].

[4] R. S. McLeod, C. J. Hopfe, and A. Kwan, 'An investigation into future performance and overheating risks in Passivhaus dwellings', Build. Environ., vol. 70, pp. 189-209, Dec. 2013.

[5] ZCH, 'Assessing Overheating Risk: Evidence Review'. Zero Carbon Hub, Mar-2015.

[6] M. Samuelson and T. Lüddeckens, 'Passivhus ur en brukares perspektiv.', Växjö University, Sweden, 2009.

[7] T. Kleiven, 'Brukerundersøkelse i Husby Amfi'. SINTEF Byggforsk, 17-Dec-2007.

[8] J. Palmer, D. Godoy-Shimizu, A. Tillson, and M. Mawditt, 'Building Performance Evaluation - Domestic Final Report', Innovate UK, Jan. 2016.

[9] S. Ruud and L. Lundin, 'Bostadshus utan traditionellt uppvärmningssystem - resultat fran tva ars matningar. SP Report 2004:31', 2004.

[10] CIBSE, 'The Limits of Thermal Comfort: Avoiding Overheating in European Buildings', CIBSE, 2013.

[11] G. J. Jenkins, M. C. Perry, and M. J. Prior, 'The climate of the United Kingdom and recent trends'. Met Office Hadley Centre, Exeter, UK, 2008.

[12] A. Wright, A. Young, and S. Natarajan, 'Dwelling temperatures and comfort during the August 2003 heat wave', Build. Serv. Eng. Res. Technol., vol. 26, no. 4, pp. 285-300, Nov. 2005.

[13] C. Rooney, A. McMichael, R. Kovats, and M. Coleman, 'Excess mortality in England and Wales, and in Greater London, during the 1995 heatwave.', J. Epidemiol. Community Health, vol. 52, pp. 482-6, 1998.

[14] S. Hajat, B. Armstrong, M. Baccini, A. Biggeri, L. Bisanti, A. Russo, A. Paldy, B. Menne, and T. Kosatsky, 'Impact of High Temperatures on Mortality: is there an added heat wave effect?', Epidemiology, vol. 17, no. 6, pp. 632-638, Nov. 2006.

[15] B. Armstrong, Z. Chalabi, B. Fenn, S. Hajat, S. Kovats, A. Milojevic, and P. Wilkinson, 'Association of mortality with high temperatures in a temperate climate: England and Wales', J. Epidemiol Community Health, vol. 65, no. 4, pp. 340-345, May 2010.

[16] Zero Carbon Hub Task Group, ‘Defining a Fabric Energy Efficiency Standard for Zero Carbon Homes: Task Group Recommendations November 2009'. Nov-2009.

[17] R. S. McLeod and C. J. Hopfe, 'Hygrothermal implications of low and zero energy standards for building envelope performance in the UK', - J. Build. Perform. Simul., vol. 6, no. 5, Mar. 2013.

[18] Mayor of London, 'London Plan (chapter five). London's response to climate change'. Jul-2011.

[19] Å. L. Hauge, J. Thomsen, and T. Berker, 'User evaluations of energy efficient buildings: Literature review and further research', Adv. Build. Energy Res., vol. 5, no. 1, pp. 109-127, 2011.

[20] HM Government, 'Approved Document ADL1A - Conservation of fuel and power in new dwellings. (2010 edn).' Oct-2010.

[21] ODPM, 'Approved Document ADL1A Conservation of fuel and power in new dwellings. (2006 edn.)'. Office of the Deputy Primeminister (ODPM), 06-Apr-2006.

[22] CLG, 'Code for Sustainable Homes: Technical guide - October 2007 - Planning, building and the environment - Department for Communities and Local Government'. Oct-2007. 
[23] ZCH, 'Building profiles | Zero Carbon Hub', 2016. [Online]. Available: http://www.zerocarbonhub.org/building-profiles. [Accessed: 19-Sep-2016].

[24] Passive House Trust, 'UK Passivhaus Project Gallery', Jul-2016. [Online]. Available: http://www.passivhaustrust.org.uk/projects/. [Accessed: 22-Sep-2016].

[25] HM Treasury, 'Fixing the foundations: Creating a more prosperous nation'. Jul-2015.

[26] Mayor of London, 'Housing Supplementary Planning Guidance. London Plan 2016 Implementation Framework'. Greater London Authority, Mar-2016.

[27] Mayor of London, 'Energy Planning - GLA Guidance on preparing energy assessments'. Greater London Authority, Mar-2016.

[28] ODPM, 'Approved Document F- Ventilation. (2006 edn.)’. 2006.

[29] HM Government, 'Approved Document Part F - Ventilation (2010 edn.)'. HM Government, 2010.

[30] BSI, 'BS 59251991 AMD 1 Code of practice for ventilation principles and designing for natural ventilation (AMD 8930) dated 15 December 1995 - IHS, Inc'. 15-Dec-1995.

[31] BSI, 'BS 8213-1:2004 - Windows doors and rooflights. Design for safety in use and during cleaning of windows, including door-height windows and roof windows - code of practice'. 01-Oct-2004.

[32] Greater London Authority, 'The London Plan. The Spatial Development Strategy for London. Policy 5.6 Decentralised energy in development proposals | London City Hall'. Greater London Authority, Mar2015.

[33] HM Treasury, 'Budget 2016 - Policy paper'. 16-Mar-2016.

[34] S. K. Brown, 'Indoor Air Quality'. CSIRO, 1997.

[35] DECC, 'UK Domestic energy over time'. 2010.

[36] A. D. Peacock, D. P. Jenkins, and D. Kane, 'Investigating the potential of overheating in UK dwellings as a consequence of extant climate change', Energy Policy, vol. 38, no. 7, pp. 3277-3288, Jul. 2010.

[37] CIBSE, 'TM52: The Limits of Thermal Comfort: Avoiding Overheating in European Buildings'. 2013.

[38] ZCH, 'Overheating In Homes - Drivers of Change'. 2015.

[39] ASHRAE, 'ASHRAE 55-2013 - Thermal Environmental Conditions for Human Occupancy'. 2013.

[40] T. Bedford, The Warmth Factor in Comfort at Work: A Physiological Study of Heating and Ventilation. H. M. Stationery Office, 1936.

[41] J. F. Nicol, I. A. Raja, A. Allaudin, and G. N. Jamy, 'Climatic variations in comfortable temperatures: the Pakistan projects', Energy Build., vol. 30, no. 3, pp. 261-279.

[42] M. A. Humphreys, J. F. Nicol, and I. A. Raja, 'Field Studies of Indoor Thermal Comfort and the Progress of the Adaptive Approach', Adv. Build. Energy Res., vol. 1, no. 1, 2007.

[43] P. O. Fanger, 'Calculation of Thermal Comfort, Introduction of a Basic Comfort Equation', ASHRAE Trans., vol. 73, no. 2, 1967.

[44] R. de Dear, K. G. Leow, and A. Ameen, 'Thermal comfort in the humid tropics. Part I. Climate chamber experiments on temperature preferences in Singapore', ASHRAE Trans., vol. 97, no. 1, pp. 874-879, 1991.

[45] ISO, 'ISO 7730:2005 - Ergonomics of the thermal environment -- Analytical determination and interpretation of thermal comfort using calculation of the PMV and PPD indices and local thermal comfort criteria'. 2005.

[46] A. J. Watts, 'Hypothermia in the aged: a study of the role of cold-sensitivity', Environ. Health Res., vol. 5, pp. 119-126, 1971.

[47] K. J. Collins, 'Temperature requirements in old age', Build. Serv. Eng. Res. Technol., vol. 1, no. 4, pp. 165172, Nov. 1980.

[48] World Health Organisation, 'WHO - health impact of low indoor temperatures.', 1987.

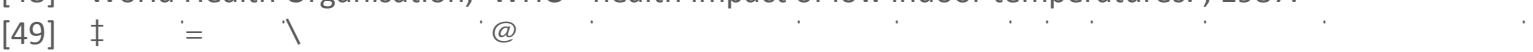

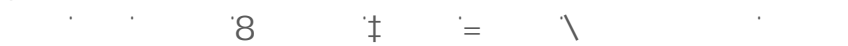

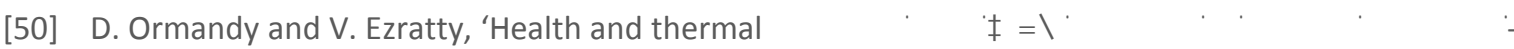
WRAP: Warwick Research Archive Portal', Energy Policy, vol. 49, pp. 116-121, 2012.

[51] DCLG, 'Housing Health and Safety Rating System: Guidance for Landlords and Property Related Professionals'. 2006.

[52] ODPM, 'Housing Health and Safety Rating System: Operating Guidance'. 2006.

[53] NAME WITHHELD, 'O\&Ms Construction - Project Handover Documentation', 2016. [Online]. Available: http://www.NAMEWITHELD.co.uk/. [Accessed: 12-Jun-2016].

[54] Eltek, 'Genll series -applications and key features'. Feb-2013.

[55] Eltek Ltd, 'Eltek Data Loggers - Sensors', Eltek - specialist data loggers, 2016. [Online]. Available: http://www.eltekdataloggers.co.uk/sensors.html\#tabs-temp-intro. [Accessed: 07-Jul-2016]. 
[56] R. Wilby, 'Past and projected trends in London's urban heat island', Weather, vol. 58, Jul. 2003.

[57] T. Kershaw, M. Sanderson, D. Coley, and M. Eames, 'Estimation of the urban heat island for UK climate change projections', Build. Serv. Eng. Technol., vol. 31, no. 3, May 2010.

[58] Met Office, 'Hampstead climate information - Met Office', 2016. [Online]. Available: http://www.metoffice.gov.uk/public/weather/climate/gcpv7fnqu. [Accessed: 17-Mar-2016].

[59] V. Agafonkin, 'SunCalc - sun position, sunlight phases, sunrise, sunset, dusk and dawn times calculator', 2016. [Online]. Available: http://suncalc.net/. [Accessed: 22-Jun-2016].

[60] ISO, 'ISO 7726 - Ergonomics of the thermal environment -- Instruments for measuring physical quantities'. International Standards Organisation, 2002.

[61] R. McMullan, Environmental Science in Building, 7th edition. Palgrave Macmillan, 2012.

[62] CIBSE, ‘Guide A Environmental Design - 2015 Edition'. 2015.

[63] HM Government, 'Approved Document F. Ventilation, 2010 edition incorporating 2013 amendments.' NBS, Oct-2015.

[64] DECC, 'SAP 2009_9-90'. DECC, Mar-2011.

[65] M. A. Humphreys, 'The influence of season and ambient temperature on human clothing behaviour.', Indoor Clim., pp. 699-714, 1979.

[66] CIBSE, 'CP1: Heat Networks: Code of Practice for the UK'. CIBSE, Jul-2015.

[67] HM Government, 'Domestic Ventilation Compliance Guide - 2010 Edition'. NBS, Jul-2011.

[68] C. J. Hopfe and R. S. McLeod, The Passivhaus Designer's Manual: A technical guide to low and zero energy buildings. Routledge, 2015.

[69] BRE, 'Home Quality Mark: Technical Manual. SD232: 0.0 (Beta England) - 2015'. 2015.

[70] CIBSE, 'AM11 Building Performance Modelling'. CIBSE - Building Services Knowledge, Jul-2015.

[71] CIBSE, 'TM48: Use of Climate Change Data in Building Simulation'. CIBSE - Building Services Knowledge, Oct-2009. 